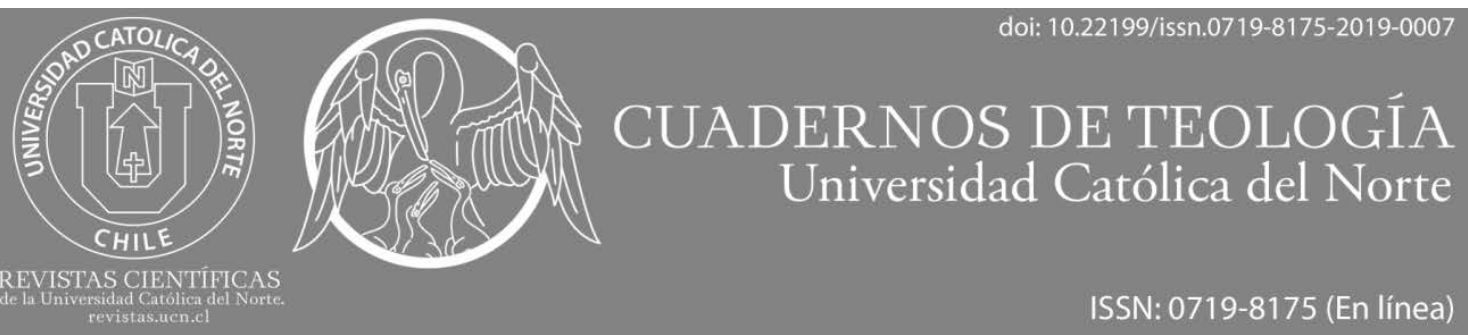

\title{
¿Están la ciencia y la fe en conflicto? Depende de lo que se entienda por 'conflicto'
}

\section{Are science and faith in conflict? It depends on what you mean by 'con- flict'}

\author{
Judith M. Ayala Choque* (D) https://orcid.org/0000-0003-0915-3524 \\ Raúl Esperante** (iD https://orcid.org/0000-0001-8422-2927 \\ *Universidad Adventista de Bolivia, Vinto, Cochabamba. Vicerrectora Académica. MSc, Loma Linda U. (EE.UU). \\ judiayala@hotmail.com \\ ${ }^{* *}$ Geoscience Research Institute. Loma Linda, CA, EE.UU. Catedrático Investigador. PhD. en Paleontología, Loma \\ Linda U. (EE.UU). resperante@llu.edu \\ (cc) BY
}

\section{Resumen:}

La historia de la ciencia muestra que la religión cristiana no ha estado en oposición o conflicto con la ciencia, sino más bien en estrecha colaboración y entendimiento. Los principios en los que se basa el cristianismo y los atributos divinos favorecen el conocimiento humano y la investigación de la naturaleza. En el siglo XIX y en especial con el surgimiento de la teoría darwinista de la evolución, la idea se conflicto se afianzó en numerosos ambientes académicos. Sin embargo, un análisis en epistemológico indica que el conflicto no es acerca de la evidencia que la ciencia y la religión puedan presentar, o acerca de los objetos de estudio mismo. No existe tal conflicto cuando se entienden bien la fe y la ciencia, y para ello hay que ser humildes en ambos y reconocer que no tenemos todo el conocimiento necesario para la verdad. Pero sí existe un conflicto en cuanto a quién tiene la autoridad acerca de la verdad, especialmente la verdad final, aquella que va más allá de lo material, y un conflicto en cuanto a la existencia o no de un propósito para la naturaleza y, en particular, del ser humano.

Palabras Clave: Religión y ciencia; Propósito humano; Moralidad; Materialismo.

\begin{abstract}
:
History of science shows that the Christian religion has not been in opposition or conflict with science, but rather in close collaboration and understanding. The principles on which Christianity is based and the divine attributes favor human knowledge and investigation of nature. In the nineteenth century and especially with the emergence of the Darwinian theory of evolution, the idea of conflict became entrenched in many academic environments. However, an epistemological analysis indicates that the conflict is not about the evidence that science and religion may present, or about the objects of study itself. There is no such conflict when faith and science are well understood, and for this we must be humble in both and recognize that we do not have all the necessary knowledge for the truth. But there is a conflict as to who has the authority over the truth, especially the final truth, that which goes beyond the material, and a conflict as to the existence or not of a purpose for nature and, in particular, of the human being.

Keywords: Religion and science; Human purpose; Morality; Materialism.
\end{abstract}




\section{Introducción}

"He tenido que limitar la razón para hacerle sitio a la fe". Esta afirmación de Inmanuel Kant (1724-1804) puede considerarse como prólogo de lo que en los últimos dos siglos ha sido en el mundo académico la progresiva reducción del valor de la fe y la magnificación de la razón con la correspondiente coronación de la ciencia. Este racionalismo caracterizó a la última etapa de la Época Moderna, con la razón y la ciencia conquistando todos los ámbitos intelectuales y sociales y apartando a un lado otras realidades, incluyendo la religión, dejando la fe fuera del ámbito cognitivo real. Ya avanzados en el Renacimiento dentro del siglo XV, el secularismo y el desarrollo de la ciencia en Europa Central, Italia y Gran Bretaña, los desarrollos en la navegación y la geografía, la publicación de numerosos libros y la apertura de las bibliotecas al público, trajeron a la sociedad europea la impresión de que la razón aplicada a la ciencia tenía el potencial de mejorar la sociedad. El ensayista Rafael Alvira afirma que la razón se fue revistiendo con los mejores atributos de objetividad, experimentación, verificación, exactitud matemática y pertenencia al público (Alvira Domínguez, 2002 , p. 16). La ciencia era atractiva porque aportaba soluciones y respuestas a la sociedad, era comunicativa y universal. En oposición, la razón era subjetiva, emocional, inverificable, imprecisa y privada. Una de las dicotomías más marcadas era la de claridad (razón/ciencia) y oscuridad (fe). Tanto se asoció la fe con la oscuridad que los siglos medievales recibieron el nombre de "siglos oscuros", algo que ahora muchos historiadores consideran injustificado (Hannam, 2011; Schmidt, 2004; Stark, 2004). La asociación de la ciencia con lo objetivo la convirtió en comprensible y atractiva al intelecto público, mientras que la fe pasó a ser subjetiva y personal, perteneciente a cada individuo, y existente solamente en la esfera de lo sentimental y privado. Cuando antes era la Biblia la que explicaba el mundo, ahora es la ciencia. Esta visión racionalista de la ciencia y la fe llevaron a un progresivo desprestigio de la religión, con el conocimiento verdadero surgiendo de la ciencia por el uso de la razón. Por eso, decía Kant, había que hacerle sitio a la fe.

La coronación de la razón no sería permanente. Rafael Alvira indica que, después de dos siglos de Modernidad, se llegó a la "crisis de la racionalidad" en el siglo XX, la cual "es la venganza de la naturaleza. Se magnificó tanto la razón que se puso en crisis la fe; pero ahora también la razón está en crisis, porque no sabemos ya qué es" (Alvira Domínguez, 2002, p. 18). No obstante, y a pesar de la crisis de la razón, a lo largo del siglo XX y en lo que llevamos del siglo XXI los científicos han abrazado el modelo racionalista que los filósofos Ilaman como evidencialismouna teoría se acepta solo si hay buenas razones (o evidencia) para pensar que es verdad. Actualmente, la discusión sobre el conflicto entre la fe y la ciencia ya no se presenta desde la invalidez de la fe sino desde el 'innecesidad', 'su supuesto nulo valor explicativo. Es por ello que muchos científicos encuentran que el conflicto entre la ciencia y la religión deriva de que la primera puede aportar evidencias para lo que afirma, pero la segunda no. Debido a esto, muchos científicos han afirmado la superioridad (e incluso) singularidad de la ciencia sobre la religión. El evidencialismo ha llevado a la cosmovisión del cientificis-

\footnotetext{
${ }^{1}$ La palabra innecesidad no se halla en el Diccionario de la Real Academia de la Lengua Española. Aquí la uso por su valor descriptivo.
} 
mo, una forma de imperialismo científico que sostiene que la ciencia, y solo la ciencia, puede dar respuesta a todas las preguntas sobre el mundo y la vida humana y solo por medio de la ciencia podemos llegar a la verdad.

Algunos científicos contemporáneos afirman que la ciencia ya ha suplantado a Dios-o al menos está en camino de hacerlo. Para ellos, la ciencia en general, y en especial la biología, cuestiona la religión tradicional judeo-cristiana, al punto de convertirla en irrelevante en cuestiones de la razón. Darwin ha hecho innecesaria la fe-dicen estos pensadores. Esta idea distorsionada de la ciencia ha contribuido a la percepción de un conflicto con la religión, idea que todavía es común en ciertas esferas académicas. De hecho, en nuestras conferencias con estudiantes y profesores a menudo oímos la afirmación, "no se puede ser cristiano y científico a la vez", o "para ser un científico de verdad no se puede creer en la religión", como si la práctica de la religión y la ciencia fueran incompatibles y hasta enemigas. Según ellos, no hay posibilidad de conjugar ciencia y fe, puesto que se trata de dos maneras incompatibles de mirar la realidad. 0 se es científico o se es creyente, pero no se puede ser las dos cosas al mismo tiempo; los dos reinos son excluyentes. En esta postura se sitúan tanto científicos como creyentes, enfrentándose las posturas de los científicos reduccionistas y materialistas y de los creyentes fundamentalistas.

\section{El origen de la idea de conflicto}

Muchos autores han notado la estrecha histórica relación entre el cristianismo y el desarrollo de la ciencia (Bar- bour, 2004; Brooke, 1991; Hannam, 2011; Harrison y Lindberg, 2011; Lindberg y Numbers, 1987; Stark, 2004). Es un hecho bien conocido que la mayoría de los científicos de la historia occidental fueron cristianos creyentes. Muchos de los grandes avances científicos fueron hechos por hombres que no sólo eran creyentes, sino que tenían una motivación religiosa para el descubrimiento y el avance del conocimiento. De hecho, la mayoría del avance científico hasta el siglo XVI, y en algunos casos después, fue llevado a cabo por monjes en monasterios y otros clérigos en instituciones teológicas (Schmidt, 2004; Stark, 2004). La religión cristiana fomentaba el interés en el descubrimiento y la experimentación científica y la fe no era un impedimento para su trabajo analítico, sino que les motivaba a la formulación de hipótesis. El físico Joseph L. Spradley señala que:

"'Pronto en el pensamiento cristiano surgió una manera de entender la divinidad de Cristo que llevó a un fundamento más sólido para la ciencia teórica. Comenzando con las fuentes bíblicas [Jn 1:1-4; Flp 2:5-11; Col 1:15-20], los pensadores cristianos desarrollaron el concepto griego de Logos y lo aplicaron a Cristo como la razón y la Palabra de Dios en la creación del mundo. La doctrina del Logos juntamente con la doctrina de la creación proporcionó la base para la presuposición en la ciencia de que la naturaleza es un cosmos ordenado, lo cual es en cierto grado inteligible al conocimiento humano. Ello reforzó la creciente convicción cristiana de la unidad de la creación, lo cual llevó a la derrota de la tendencia pagana a deificar la naturaleza y a la visión griega de la perfección celestial, con- 
ceptos ambos que habían impedido

el pleno desarrollo de la

cia" ${ }^{2}$ (Spradley, 2005, p. 28).

Spradley afirma que los valores y principios filosóficos y epistemológicos cristianos favorecieron el conocimiento y desarrollo científico porque acercaban la creación al ser humano, y porque la creación se entendía como inteligible. Incluso conceptos esencialmente religiosos como la humanidad y la divinidad de Cristo y la doctrina de la encarnación influyeron en el desarrollo del pensamiento científico dentro del cristianismo de los primeros siglos al promover la apreciación por el descubrimiento, el trabajo, la realidad de la materia y la bondad de la creación (según Génesis, la creación es muy buena). La fe cristiana conducía a la exploración, al conocimiento y la investigación, y por ello durante muchos siglos se consideró a la ciencia y la Escritura como amigos, no enemigos. Esta idea continuó en la vida profesional de grandes figuras como los fundadores de la Física moderna (Newton, Boyle, Faraday, Maxwell-eran devotos cristianos) hasta la actualidad (con científicos como John Polkinghorne, Arthur Peacocke, Denis Alexander, Francis Collins, Michael Behe, Leonard Brand, Guillermo González, y muchos otros). ¿Por qué entonces se habla de un conflicto entre la fe, o religión, y la ciencia?

Desafortunadamente, la narrativa del conflicto entre la ciencia y la religión persiste en la mente del público debido a publicaciones de varios científicos y filósofos del llamado Nuevo Ateísmo, incluyendo Dios no es bueno, de Christopher Hitchens (2008) y El fin de la fe. Religión, terror, y el futuro de la razón de Richard Ha-

\footnotetext{
${ }^{2}$ Las traducciones al español de las citas en inglés
} han sido realizadas por los autores de este artículo. rris (2007). Pero su origen es anterior, hasta la segunda mitad del siglo XIX con el surgimiento del positivismo y la teoría darwinista de la evolución. Dos libros de esa época jugaron un papel muy influyente en el establecimiento de la idea de confrontación entre ciencia y religión, concretamente los escritos de John William Draper (1874) - History of the conflict between science and religión - y Andrew Dickson White (1986) -A history of the warfare of science with theology in Christendo -, en parte por el deseo de crear una esfera profesional separada para la ciencia independiente de la élite clerical que controlaba las universidades y las escuelas. Ambos libros se fundamentan en el positivismo y en una visión altamente antireligiosa de la historia que hicieron cimentar la idea de conflicto entre la ciencia y la religión (o entre la ciencia y las instituciones religiosas) en el pensamiento de finales del siglo XIX. Esta idea de conflicto estuvo magnificada por el enfrentamiento que Thomas $\mathrm{H}$. Huxley (defensor del darwinismo y conocido con el "bulldog de Darwin") y el obispo anglicano Samuel Wilbeforce tuvieron en una reunión en Oxford de la British Association al año siguiente de la publicación de El origen de las especies de Charles Darwin (1859). La percepción general que ha quedado es que ese enfrentamiento fue la personificación de un conflicto ideológico mucho más profundo entre una religión anclada en un texto sagrado del pasado que afirma la creación sobrenatural y una ciencia moderna que avanzaba con nuevos descubrimientos e invenciones, incluyendo el origen materialista de la vida. En años recientes los historiadores de la ciencia han mostrado que no hubo tal enfrentamiento, y que la idea de que Huxley derrotó a Wilbeforce es un mito creado por aquellos que querían celebrar el triunfo de 
la ciencia naturalista sobre la religión, en la línea de agenda ideológica de White y Draper (Brooke, 2001; James, 2005).

Lejos de originar amplio conflicto, la realidad es que el libro de Darwin no encontró una seria oposición entre los cristianos porque muchos de ellos ya albergaban la idea de que una lectura literal del relato del Génesis no era sostenible. La popular interpretación de la teoría de Darwin en términos de "supervivencia del más fuerte" parecía encajar muy bien con la realidad de la Inglaterra victoriana de la época en la que la ciencia estaba suplantando a los clérigos religiosos en la lucha por la supremacía intelectual y la autoridad. En Gran Bretaña, Europa Central y en Norteamérica las ideas de largas edades postuladas por los geólogos se habían extendido y la mayoría de los pensadores aceptaba que la historia de la tierra era mucho más larga que lo que dice el Génesis, y que el registro fósil muestra que a lo largo de esa larga historia ha habido muchas poblaciones diferentes de animales y plantas (Bowler, 2009; Bowler, 2012). En general, los darwinistas no tuvieron que luchar contra los creyentes religiosos, y en muchos sentidos no hubo un conflicto abierto. Especialmente en Gran Bretaña y Norteamérica, los científicos querían saber cómo explicar la aparición en el registro fósil de las diversas formas de vida compleja. Los naturalistas de principio del siglo XIX atribuían ese progresivo aumento de complejidad a periódicas y sucesivas creaciones seguidas de extinciones masivas, idea firmemente defendida por el científico francés George Cuvier (17691832). Pero a mediados de ese siglo los naturalistas comenzaron a adoptar la idea de que los seres vivos tenían alguna forma de "ley de la creación" divinamente programada para actuar en los organismos produciendo cambios-lo que entonces se llamaba "transmutación"-de unas especies a otras. Fue Robert Chambers en su libro Vestiges of the Natrural History of Creation quien promovió esa idea en 1844 con una argumentación más elaborada (Chambers, 1844).

La publicación El Origen de las Especies en 1859 por Charles Darwin pareció proporcionar el mecanismo para esos cambios (transmutaciones) en las especies, y con ello una explicación para la existencia biológica tal como se conocía en aquel entonces. Tal como han demostrado numerosos estudios recientes basados en las cartas y otros escritos de Darwin, la adopción de los principios evolucionistas por una mayoría de teólogos y científicos académicos y un sector de la sociedad secular en la segunda mitad del siglo XIX no fue tanto debido a los argumentos científicos que Darwin presentaba, ni tampoco porque era una buena arma de ataque contra el cristianismo tradicional, sino porque las ideas de Darwin coincidían con la coyuntura social de la Gran Bretaña del siglo XIX: libre mercado y competencia entre las empresas, superioridad natural de la clase media y de sus valores, lucha por el éxito y supervivencia de los mejor acomodados (Desmond y Moore, 1991; Papp, 1993).

El evolucionismo de Darwin proporcionaba un fundamento teóricocientífico para el liberalismo victoriano inglés y sus valores y ello era bien visto por muchos cristianos. Cierto es que Darwin fue un observador cuidadoso de la naturaleza, pero sus ideas tienen una alta carga de prejuicios sociales de aquella época, algunos de los cuales serían considerados ahora como inaceptables, racistas, machistas, y absolutamente erróneos. También es cierto que la mayoría de los que inicialmente aceptaron el darwinismo 
lo hicieron solo de una manera general, como principio de cambio biológico, sin abrazar completamente los mecanismos de variación y selección natural que Darwin proponía. Varios significativos investigadores de la época proponían ideas de evolución más comprometedoras con la religión cristiana, aceptando formas de evolución teísta con mayor o menor intervención divina en los procesos naturales ${ }^{3}$.

A pesar del creciente acomodo del darwinismo en el cristianismo en el comienzo del siglo XX, los pensadores que defendían la idea de conflicto buscaron apoyo para su idea en la manera en que los científicos mismos consideraban la fe. En esa época, el psicólogo James H. Leuba afirmó que la religión era una creación de la imaginación humana en lugar de una respuesta racional a un cosmos divinamente ordenado. Leuba razonó que los científicos-como aquellos que más conocen acerca del mundo natural-serían los primeros en aceptar esta verdad y como consecuencia los menos probables en creer en Dios o asistir a la iglesia. Leuba encontró prueba de ello al entrevistar a la élite científica de la National Academy of Sciences (EEUU) y hallar que estos científicos eran mucho menos religiosos que otros norteamericanos, concluyendo que sólo era cuestión de tiempo que la ciencia sobrepasara la religión (Leuba, 1934). Al mismo tiempo, el positivismo lógico de la primera mitad del siglo XX se asignó la victoria en la supuesta confrontación en-

\footnotetext{
3 Por ejemplo, el anatomista británico Richard Owen escribió una crítica negativa de El Origen de las Especies, pero luego propuso su propia teoría de "derivación" de las especies de acuerdo con las leyes pre-programadas en los organismos. El astrónomo británico John Frederick William Herschel rechazó la selección natural, pero creía en una idea de evolución guiada por Dios. En Norteamérica, el botánico Asa Gray defendió la teoría de la evolución de Darwin, aunque indicando que la variación debe darse en "líneas beneficiosas" que evitan las variaciones dañinas.
}

tre la ciencia y el cristianismo al establecer las normas para llegar a la verdad-solo el conocimiento empíricamente verificable es válido; todas las demás formas de conocimiento son opiniones, sensaciones, emociones y sin fundamento verificable. Este postulado filosófico, que a su vez no era verificable en sí mismo y por tanto carecía de poder convincente, se convirtió en el punto de vista dominante en las ciencias durante al menos cincuenta años, un tiempo en el que se hicieron los grandes descubrimientos de la ciencia contemporánea, desde la complicada estructura del interior de la célula, el ADN, el avance de la medicina, la tecnología, y los viajes espaciales. La ciencia y la razón se establecían como reinantes.

\section{El conflicto en la narrativa re- ciente}

En las décadas recientes, numerosos filósofos, historiadores y científicos han argumentado de manera convincente la insostenibilidad de la narrativa del conflicto entre ciencia y religión, en especial, el cristianismo (Brand, 2003; Hutchinson, 2007; Larsen, 2008; McGrath, 2015). Sin embargo, todavía hay científicos que se aferran a la idea de conflicto, incluso desde el campo religioso. Algunos científicos afirman que, aunque la ciencia y la fe sean incompatibles, no necesitan estar en conflicto. Para una breve exposición de las diversas opiniones cerca de la relación entre la ciencia y la fe, ver Tabla 1. La ciencia y la religión han de verse como diferentes ventanas al mundo en el mismo universo, como diferentes maneras de conocer acerca de diferentes tipos de cosas. Esta es la posición que adopta la National Academy of Science de Estados 
Unidos en su librito Science and Creationism del año 1984. El presupuesto

Tabla 1: La relación entre la ciencia y la fe en autores recientes

\begin{tabular}{|c|c|c|}
\hline Autores & Tipo de relación & Descripción \\
\hline \multirow{4}{*}{$\begin{array}{l}\text { lan Barbour } \\
\text { (2004) }\end{array}$} & Conflicto & La ciencia y la religión son rivales y están en conflicto. \\
\hline & Independencia & $\begin{array}{l}\text { La ciencia y la religión son dominios separados del conocimiento } \\
\text { que deben mantenerse separados. }\end{array}$ \\
\hline & Diálogo & $\begin{array}{l}\text { Entre la ciencia y la religión hay muchos puntos de convergen- } \\
\text { cia, que hacen posible el diálogo, no el conflicto. }\end{array}$ \\
\hline & Integración & $\begin{array}{l}\text { Hay colaboración entre la ciencia y la religión para encontrar la } \\
\text { verdad. }\end{array}$ \\
\hline \multirow[t]{3}{*}{$\begin{array}{l}\text { Leonard Brand } \\
\text { (2003) }\end{array}$} & Dominios separados & $\begin{array}{l}\text { Ninguna interacción entre ellas, son dominios separados. Se } \\
\text { excluyen las explicaciones sobrenaturales. }\end{array}$ \\
\hline & Dominios en paralelo & $\begin{array}{l}\text { Se aceptan ambas como fuente de verdad, pero no se permite } \\
\text { ninguna interacción entre ellas. }\end{array}$ \\
\hline & $\begin{array}{l}\text { Interacción con predominio } \\
\text { de Dios en el pensamiento }\end{array}$ & $\begin{array}{l}\text { Hay una interacción entre la ciencia y la religión, ambas contribu- } \\
\text { yen a la verdad; la inclusión de la acción de un ser sobrenatural } \\
\text { puede ayudar a explicar mejor la naturaleza. }\end{array}$ \\
\hline \multirow[t]{4}{*}{$\begin{array}{l}\text { Humberto Rasi } \\
\text { (2003) }\end{array}$} & Fideísmo & $\begin{array}{l}\text { La fe ignora o minimiza el rol de la razón como medio para alcan- } \\
\text { zar la verdad última. }\end{array}$ \\
\hline & Racionalismo & $\begin{array}{l}\text { La razón humana cuestiona, ataca y eventualmente destruye la fe } \\
\text { religiosa. }\end{array}$ \\
\hline & Dualismo & $\begin{array}{l}\text { La fe y la razón actúan en esferas diferentes, de modo que ni se } \\
\text { confirman ni se contradicen. }\end{array}$ \\
\hline & Sinergia & $\begin{array}{l}\text { La fe y la razón cooperan y se ayudan mutuamente en la búsque- } \\
\text { da de la verdad y el cometido personal a la misma. }\end{array}$ \\
\hline \multirow[t]{4}{*}{$\begin{array}{l}\text { E. Edward Zinke } \\
\text { (2004) }\end{array}$} & Único & $\begin{array}{l}\text { La ciencia es el único fundamento para el conocimiento, tanto si } \\
\text { procede de la naturaleza o si procede de la Biblia. }\end{array}$ \\
\hline & Independiente & La verdad es verdad independientemente donde se encuentre. \\
\hline & $\begin{array}{l}\text { Dominios radicalmente } \\
\text { separados }\end{array}$ & $\begin{array}{l}\text { La ciencia trata exclusivamente acerca de la naturaleza y la Biblia } \\
\text { trata exclusivamente acerca de la religión. No hay intersección } \\
\text { entre ellas. }\end{array}$ \\
\hline & $\begin{array}{l}\text { Dios se ha revelado a sí } \\
\text { mismo en la naturaleza y la } \\
\text { Biblia }\end{array}$ & $\begin{array}{l}\text { La revelación procede de Dios; la ciencia y religión pueden estu- } \\
\text { diarse desde el punto de vista bíblico de la Biblia y la Biblia sola. }\end{array}$ \\
\hline \multirow{4}{*}{$\begin{array}{l}\text { Denis R. Alexander } \\
\text { (2007) }\end{array}$} & Conflicto & La ciencia y la religión están en oposición. \\
\hline & NOMA & $\begin{array}{l}\text { La ciencia y la religión se encuentran en compartimentos diferen- } \\
\text { tes y totalmente separados, por lo tanto, no hay conflicto. }\end{array}$ \\
\hline & Fusión & $\begin{array}{l}\text { La ciencia y la religión se integran, buscar unir el conocimiento } \\
\text { científico y la religión. }\end{array}$ \\
\hline & Complementariedad & $\begin{array}{l}\text { La ciencia y la religión hablan de temas de la misma realidad, } \\
\text { pero desde perspectivas diferentes, con la finalidad de comple- } \\
\text { mentarse. }\end{array}$ \\
\hline \multirow{3}{*}{$\begin{array}{l}\text { Mikael Stenmark } \\
\text { (2004) }\end{array}$} & Independencia & No hay solapamiento entre la ciencia y la religión. \\
\hline & Nonismo & Hay una unión de dominios de la ciencia y la religión. \\
\hline & Contacto & Hay un solapamiento o intersección. Entre la ciencia y la religión. \\
\hline
\end{tabular}


subyacente en esta posición es que la ciencia y la religión no están en conflicto siempre que la religión evite explicar el mundo natural. Esta no es la única declaración de no-conflicto, y, de hecho, numerosas publicaciones desafían la idea de conflicto o guerra entre la religión y la ciencia. Por ejemplo, el Catecismo Católico de los Estados Unidos para los Adultos, establece la relación entre la fe y la razón (o ciencia) de la siguiente manera:

"La fe busca comprender y es amiga de la razón. La fe como gracia o don de Dios hace posible ganar entendimiento de todo lo que Él nos ha revelado, incluyendo la totalidad de su designio, así como los muchos misterios de la fe. Crecer en el entendimiento de la Revelación de Dios es un proceso para toda la vida. La teología y la catequesis nos ayudan. Nunca entendemos completamente estos misterios divinos, pero a menudo obtenemos ideas profundas sobre ellos. En este contexto, la fe y la razón trabajan juntas para descubrir la verdad. El suponer que el pensamiento humano o la investigación científica pueden o deberían estar en conflicto con la fe es una idea equivocada porque esta posición niega la verdad básica que dice que todo ha sido creado por Dios. Las investigaciones eruditas y científicas que se llevan a cabo de una manera fiel a la razón y a la ley moral no estarán en conflicto con la verdad como ésta ha sido revelada por Dios" (Comité ad hoc, 2007, p. 38).

El defensor del punto de vista del conflicto puede argumentar que, aunque históricamente no haya habido guerra (al contrario de lo que White y Draper habían afirmado) sino más bien cooperación, los desarrollos recientes de la ciencia sí han implicado un conflicto con la religión, por ejemplo, en cuanto a los modelos sobre orígenes de la vida, el origen de la moralidad, etc., lo cual ha llevado a algunos al rechazo de la religión. Por ejemplo, el historiador de la ciencia William Provine piensa que "quedan muy pocos biólogos evolucionistas que sean verdaderamente religiosos. La mayoría de ellos son ateos, y muchos han llegado a esa convicción partiendo de su entendimiento de los procesos evolutivos y otras ciencias" (Provine, 1988a). De hecho, Provine afirma que:

"las aplicaciones de la ciencia moderna, [son] claramente inconsistentes con la mayoría de las tradiciones religiosas. No existen principios con propósito en la naturaleza. La evolución orgánica ha ocurrido por medio de varias combinaciones de deriva genética al azar, selección natural, herencia mendeliana y muchos otros mecanismos sin propósito. Los humanos son máquinas orgánicas complejas que mueren completamente sin que sobreviva el alma o el espíritu. Los humanos y otros animales toman decisiones frecuentemente, pero éstas están determinadas por la interacción de la herencia con el ambiente y no son el resultado de la libre elección. No existen leyes morales o éticas inherentes, ni tampoco principios guiadores absolutos para la sociedad humana. Al universo no le importamos y nosotros no tenemos un significado fundamental en la vida" (Provine, 1988b). 
Provine cree que la ciencia contemporánea "concluye directamente" que no hay un propósito cósmico, no hay Dios,

(Provine, 1988a). Para Provine no hay posibilidad alguna de diálogo, entendimiento, y mucho menos integración entre la ciencia y la religión. La ciencia excluye, anula y hace irrelevante la religión y sus principios, y en ese sentido están en conflicto. Otros autores excluyen la religión de maneras más sutiles. En su libro Una breve historia del tiempo, Stephen Hawking dice que el modelo del Big Bang sugiere que el universo surgió enteramente a través de fuerzas autónomas, sin la intervención de entidades divinas (Stephen Hawking, 1988). Leon M. Lederman, que ganó el Premio Nobel de Física en 1988, dice que la ciencia no ha revelado ninguna prueba de lo divino, y aunque "en los bordes de la ciencia hay cosas desconocidas, y eso deja espacio para la existencia de un creador, hay mucho menos espacio que hace 50 años". Él dice que "El espacio disponible para Dios parece reducirse" (Citado en Katz, 2004, p. 234).

Algunos autores van más allá e indican que la ciencia y la religión son incompatibles, generalmente inclinándose por favorecer la ciencia en la búsqueda de la verdad y la explicación de la existencia humana. Por ejemplo, Sean Carroll, cosmólogo y profesor de física del California Institute of Technology, afirma abiertamente en su blog que la ciencia y la religión son incompatibles porque llegan a conclusiones incompatibles. Sin embargo, antes de decir eso, reconoce que "Eso no significa, primero, que haya alguna incompatibilidad necesaria, o lógica o a priori entre la ciencia y la religión" (Carroll, 2009). Parece una contradicción de dicho autor no hay principios éticos objetivos, ni inmortalidad, y que no hay libre albedrío

que primero afirme que la ciencia y la religión sean incompatibles y que después afirme que no hay ninguna incompatibilidad necesaria, lógica o a priori. Nos parece que, si las contradicciones no existen, quizá la supuesta incompatibilidad no se deba tanto a que ambas aporten soluciones diferentes, sino a que no se saben usar ambas de manera correcta. En todo caso, sí hay muchos aspectos en los que tanto la ciencia y la religión están de acuerdo, lo cual difumina considerablemente la línea de incompatibilidad. La ciencia y la religión están de acuerdo en buscar soluciones para las enfermedades, en combatir la pobreza, en mejorar los cultivos agrícolas y obtener mejores cosechas, en numerosos aspectos del estudio y cuidado del medioambiente, etc. Puede que haya diferencias en cuanto a la metodología o alcance, pero esas diferencias también se hayan dentro del grupo de científicos independientemente de la creencia religiosa.

\section{La mayor controversia}

Probablemente el punto de conflicto más importante entre la religión y la ciencia es lo relativo al origen de la vida. ¿De dónde vienen los seres vivos $y$, en particular, los humanos? ¿Cómo hemos llegado aquí a la Tierra? ¿Cuál es la causa de la complejidad biológica? ¿Qué sentido tiene la existencia? ¿Tiene la vida humana algún propósito? Estas son preguntas importantes para el científico, el filósofo y el teólogo, e históricamente han sido fuente de debate ideológico. Muchos cristianos, judíos y musulmanes creen que el 
universo y la vida fueron creados por Dios y que Dios es un ser personal e involucrado en los asuntos humanos, y, por lo tanto, la existencia humana tiene un propósito. Para los cristianos la Escritura tiene la respuesta a esas preguntas, para otros, sin embargo, la Biblia no debe interpretarse literalmente, especialmente el relato del origen de la vida y los seres humanos, así como los milagros. Afirman que el relato del Génesis no debe tomarse como una descripción científica del origen de la especie humana, y la Biblia, en general, no debe interpretarse como un documento científico. Sin embargo, aunque un número significativo de pensadores adoptaría esta afirmación, esto no desautoriza la Escritura como un documento válido que da un modelo verdadero del origen de la existencia en la Tierra, y ello es un punto de partida para, al menos, el diálogo entre la ciencia y la fe. La aceptación de una idea por las masas no convierte a esa idea en válida, y la historia de la ciencia, la economía, y la política contiene numerosos ejemplos de esa falacia. Por otro lado, la ciencia materialista evolucionista sostiene que la vida y la diversidad biológica son el resultado de fuerzas naturales sin la intervención de ningún agente divino, y que el origen de los organismos se puede trazar a un ancestro común que vivió hace millones de años. A pesar del aparente consenso de aceptación del evolucionismo en los círculos académicos, en las tres últimas décadas la teoría neodarwinista han sufrido serios ataques científicos y filosóficos, y algunos científicos hablan abiertamente de que hay que buscar otro modelo (Depew y Weber, 2011; Koonin, 2009; Nagel, 2012; Theißen, 2009; Whitfield, 2008). Cuando encontramos que una narrativa es inadecuada para explicar la existencia debemos sentirnos libres de buscar otras narrativas que incluyan mejo- res elementos explicativos, independientemente de donde nos lleve la evidencia. Durante demasiadas décadas el estatus científico de la teoría de la evolución apoyada en el cientificismo ha actuado como un tubo con el que se limitaba nuestra visión, declarando que sólo un método de investigación y representación de la realidad es permisible. Hoy día, muchos científicos y filósofos están reaccionando a esta restricción.

Los estudios recientes sugieren que el darwinismo introdujo en el siglo XIX un conflicto ideológico en al menos tres maneras diferentes. El primero es lo que podríamos llamar conflicto de sistemas mentales opuestos. James Moore indica que los debates darwinianos crearon conflicto, pero no entre científicos y teólogos, sino dentro de las mentes individuales que experimentaron una "crisis $d e f e^{\prime \prime}$ a medida que luchaban con el sentido de los nuevos descubrimientos científicos e históricos. Según Moore, fue un "conflicto de mentes inmersas en la tradición cristiana con las ideas y las implicaciones del darwinismo" (Moore, 1981). Un segundo tipo es el discutido por Neal C. Gillespie, quien argumenta que el conflicto involucró sistemas de la ciencia en competición, con el antiguo sistema descansando en presuposiciones teológicas mientras que el nuevo, asociado a Darwin, rechazaba la religión como medio para conocer el mundo e insistía en una interpretación de la naturaleza que involucrara solo causas secundarias naturales (Gillespie, 1979). Es lo que ahora llamamos cosmovisión materialista. Un tercer tipo de conflicto involucró un choque de autoridad intelectual y moral. Frank M Turner afirma que "el conflicto entre representantes religiosos y científicos" resultó no de la hostilidad entre la ciencia progresiva y la 
teología retrógrada, como Andrew D. White atribuyó, sino de un "cambio de autoridad y prestigio... de una parte a otra de la nación intelectual", en un momento en el que los profesionales científicos trataban de impedir a los clérigos que entraran en la actividad científica y controlaran la educación (Turner, 1978).

\section{4. ¿Dónde está el conflicto?}

Por un lado, hemos visto que la historia de la ciencia nos muestra que la ciencia y la religión no han competido en conflicto, ni se han opuesto de manera excluyente. Por otro lado, varios pensadores han hallado aspectos en los que la ciencia (evolucionista) y la fe han interaccionado en conflicto. ¿Por qué esos pensadores insisten en la existencia de conflicto entre la ciencia y la fe? Nosotros sostenemos que la ciencia y la fe están en buen diálogo, se complementan bien e incluso están en armonía, con la premisa de que no conocemos todo, ni sabemos como explicar todos los fenómenos de la naturaleza en una manera que sea compatible tanto con las explicaciones de la ciencia como con las interpretaciones bíblicas. Pero reconocemos que hay matices de conflicto a nivel experiencial y a veces metodológico. Aquí nosotros queremos presentar nuestro postulado principal sobre la existencia del conflicto entre la ciencia y la fe: el conflicto no existe en cuanto a la evidencia científica o teológica; no es un conflicto de datos, de evidencias contra evidencias, sino un conflicto de cosmovisiones, paradigmas, de qué cuenta a la hora de explicar la existencia vital, es un conflicto de autoridad y es un conflicto de visión escatológica. El conflicto no existe en cuanto al qué material, sino al qué epistemológico. ¿Qué vale cuando estamos tratando de pensar y establecer los hechos y conceptos de la realidad? ¿Debemos considerar sólo la evidencia física, o también lo inmaterial, las ideas no expresadas en materia? El conflicto también existe en cuanto a quién tiene autoridad para determinar qué es verdad. Ese conflicto no se ha resuelto aún, y no parece que el progreso científico, el aumento exponencial del conocimiento necesariamente, y el profundo análisis teológico resuelvan la situación. Un tercer conflicto atañe al origen y existencia de la moralidad humana. Según el evolucionismo materialista, no existe moralidad, y los conceptos de bueno y malo son solo convenciones humanas no derivadas de lo biológico, mientras que la cosmovisión religiosa los define como establecidos desde el exterior por un ser supremo moral, cuya moralidad se expresa en un código escrito. Un cuarto conflicto entre la ciencia y la fe se relaciona con el propósito y destino de la existencia biológica, especialmente la humana. En realidad, las cuatro maneras de conflicto ideológico que identificamos se pueden resumir en una idea dual: un choque de cosmovisiones acerca de la autoridad de la ciencia y la autoridad de la religión-el lugar de cada una (si hay lugar para las dos) en la gran historia de la vida en la Tierra-y el sentido de la vida humana.

\section{El conflicto del qué epistemo- lógico}

Mucha gente que rechaza la fe (en especial, el cristianismo) lo hacen porque piensan que ésta no ofrece suficiente evidencia para ser una alternativa racional en el campo de las ideas. Cuando alguien le preguntó al famoso ateo británico Bertrand Russell por qué no creía en Dios (asumiendo que algún día Russell estaría ante Dios), el respondió que le diría a Dios, "Dios, no había suficiente evidencia. No suficiente evidencia". Esto es lo que hemos llamado al principio del ensayo como evidencialismo. Ronald H. Nash afirma que: 
"El evidencialismo a menudo parece sostener que todas las creencias son culpables a menos que se demuestre que son inocentes. En la práctica real (...) todas las creencias religiosas son culpables hasta que se pruebe su inocencia. Mientras que los no creyentes nunca están obligados a comenzar probando que Dios no existe, los creyentes están supuestamente bajo la obligación de probar que Dios existe" (Nash, 1992, p. 89).

"Este es un caso interesante", dice Nash, "de imperialismo académico". Uno se pregunta por qué no formular la declaración de la forma inversa: todas las declaraciones cientificistas son culpables a menos que se pruebe lo contrario. En la práctica, eso no se formula así porque los racionalistas cientificistas, especialmente los ateos, ponen siempre en el creyente la responsabilidad de elaborar argumentos, razones o evidencias que apoyen sus creencias. Pero no sólo eso, para los cientificistas también las razones y evidencias de los creyentes deben ser verificables dentro de los parámetros empíricos y con la metodología científica. De una manera implícita, los racionalistas parten de la base de que los postulados y afirmaciones que parten de la fe son irracionales porque no se basan en evidencia empírica. Este es un punto de conflicto epistemológico importante: la ciencia materialista determina qué es evidencia y cómo se determina qué es evidencia.

Se ha llegado así a la idea de que la ciencia, aunque ejercida por humanos falibles y con prejuicios, ha conseguido eliminar los fallos humanos y alcanzar un alto grado de pureza y exactitud, garantizada por el método científico. Como consecuencia de ello, se cree que lo que dice la ciencia es lo que vale, es la vía para alcanzar la verdad, en cualquier aspecto de la existencia. Lo que es verdad es lo que dice la ciencia, porque es pura, exacta e imparcial, libre de prejuicios. Este es el qué epistemológico en conflicto entre ciencia y fe.

Lo anterior es, por supuesto, una visión utópica de qué cuenta como verdad y cómo se llega a ella. El astrofísico Neil deGrasse Tyson describió esta visión utópica en el primer episodio de la serie de televisión Cosmos: a Spacetime Odyssey:

"Esta aventura se hace posible por generaciones de buscadores que se adhieren estrictamente a una simple serie de normas: construye sobre esas ideas que pasan el test; rechaza las que fallan; sigue la evidencia dondequiera que lleve; cuestiona todo. Acepta estos términos, y el cosmos será tuyo" ("Standing up in the milky way", 2014).

Para Tyson la única visión que es epistemológicamente válida es la materialista. Al lector pasajero le puede sonar bien este pragmatismo metodológico, pero la realidad es que las normas simples de Tyson no funcionan. Si hemos de cuestionar todo, quizá deberíamos empezar por cuestionar las simples normas de Tyson, su metodología y el fundamento de su afirmación, que no es otro que el cientificismo. Estas normas simples pueden funcionar cuando uno está tratando con sistemas o situaciones puramente mecánicas de la realidad. El otro día, mi automóvil Honda no quiso encender, ni siquiera hacía el más mínimo ruido de ignición cuando yo movía la llave de encendido. Enseguida supe que la batería se había muerto, y no hubo duda pues el test de la batería dio que tenía carga cero. Situacio- 
nes como estas hay decenas cada día. Pero también suceden situaciones y preguntas que no se resuelven con aproximaciones mecánicas o simples, y que la ciencia no puede determinar por muy precisa que sea. Son las cuestiones sobre las grandes ideas que tocan la manera en que vivimos, pensamos o decidimos. Ahí precisamente es donde el conflicto surge, cuando la ciencia trata de determinar lo que no puede determinar.

No estamos aquí defendiendo la idea de que una cosmovisión naturalista es inferior a una teísta, ni lo contrario. Somos defensores de que ciencia y religión no sólo se complementan, sino que están en armonía si se tiene el conocimiento suficiente y se deja espacio amplio para el diálogo. Pero vemos que en la comunidad de los Nuevos Ateos y muchos naturalistas en general no ven esto porque tienen un compromiso con el materialismo y el cientificismo. En palabras de C. Stephen Evans: "...confunden un compromiso con el naturalismo, que es una postura metafísica, con un compromiso con las ciencias naturales" (Evans, 2015). En realidad, el teísta también tiene compromiso con las ciencias naturales, no ve problema en buscar el conocimiento y la investigación, no tiene miedo de la ciencia, tal como la propia historia de la ciencia nos revela de los numerosos científicos que fueron religiosos o creyentes. La cuestión no está en pensar en si la ciencia daña la fe, sino en si el naturalismo, el materialismo y el cientificismo es todo lo que hay. Ahí es donde está el conflicto epistemológico. Como hemos dicho antes, no es un conflicto de evidencia contra evidencia, sino de cosmovisión materialistacientificista contra cosmovisión teísta. El materialismo cientificista no tiene una visión de narrativas interconectadas que permitan un conocimiento más completo de la realidad.

Un ejemplo ilustrativo de este choque de cosmovisiones es la resistencia inicial a la cosmología del Big Bang a mediados del siglo XX. Aunque muchos atribuyen a Albert Einstein la idea del principio del universo a una gran explosión, paradójicamente él se opuso inicialmente y de hecho atacó con dureza al auténtico descubridor, un sacerdote jesuita belga llamado Éduard Lemaître en el año 1927. Curiosamente, el término "Big Bang" fue acuñado por el astrónomo británico Fred Hoyle para referirse de manera peyorativa a las ideas del sacerdote. Sin embargo, el prestigio del sacerdote empezó a cambiar para bien. Tan sólo un par de años más tarde, el astrónomo estadounidense Edwin Hubble descubrió que las galaxias se alejan de nosotros a gran velocidad. Hubble concluyó que el universo se expande de manera uniforme y que ello señala a que hubo un inicio en el que la materia estaba toda concentrada en un punto. En los años siguientes varios investigadores hicieron desarrollos matemáticos que dieron forma a la teoría, y en 1965 se descubrió la radiación de fondo de microondas, la cual sostenía el postulado de la gran explosión. Además, medida que se hacían esos descubrimientos los científicos se daban cuenta del perfecto ajuste fino del universo: el cosmos está regido por una serie de leyes físicas que son precisas, la más mínima variación en los parámetros de esas leyes haría que el universo fuera inestable y la vida no podría existir. Algunos llegaron más allá, sugiriendo que debe haber un propósito en la existencia del universo. Sin embargo, aún cuando la teoría iba adquiriendo mayor estatura empírica, muchos cosmólogos ateos se opusieron argumentando que, si 
hubo un comienzo, entonces debe haber un creador. Hubo científicos que se opusieron a esa idea, pero la oposición no provino de la evidencia científica, sino de lo que ellos deseaban que no fuera cierta. De hecho, la evidencia científica señalaba un comienzo del universo, lo que muchos interpretan como señalando hacia un creador. Por ello los comprometidos con el materialismo y ateísmo vieron en estos descubrimientos una amenaza para el imperialismo cientificista. Actualmente muchos astrofísicos, astrónomos y físicos encuentran evidencia que muestra que el universo con su fino ajuste no ha llegado a la existencia por casualidad. De nuevo, no fue la fe, ni la oración, ni la lectura de la Biblia, sino la evidencia científica lo que llevó a los científicos a proponer un comienzo y pensar en un creador. La fe y la ciencia no necesitan estar en conflicto en cuanto a la evidencia; lo que está en conflicto es la conciencia humana.

Un último punto nos ilustra que la relación entre la ciencia y la fe y la elección entre teísmo y ateísmo pueden, en última instancia, no depender de la evidencia científica. Un estudio de los años 2005-2007 llevado a cabo por Elaine H. Ecklund y Christopher. P. Scheitle sobre las creencias y prácticas religiosas de 1646 científicos académicos norteamericanos (de la física, química, biología, sociología, economía, biología molecular, neurociencia, bioquímica y otras áreas), en 21 universidades investigadoras de élite, muestra que los profesores de ciencia de esas instituciones son significativamente menos religiosos que la población general (Ecklund y Scheitle, 2007). El 52\% de los científicos entrevistados se identifican como carentes de afiliación religiosa, comparado con sólo el $14 \%$ de la población general. Sin embargo, esta investiga- ción atribuye la falta de creencias religiosas a variables que tienen poca relación con el estudio de las ciencias de esos profesores. Los datos muestran que no es válida la idea de que los científicos simplemente abandonan sus identidades religiosas debido a su preparación profesional, a un inherente conflicto entre la ciencia y la fe, o a la presión institucional para adecuarse al conjunto. El estudio también refleja que no es mayor el porcentaje de no creyentes en el mundo académico de las ciencias naturales en contraste con las ciencias sociales, sino al revés-los científicos en ciencias sociales tienden a ser menos religiosos que los científicos en ciencias naturales. También resulta falsa la presuposición de que el convertirse en científicas necesariamente lleva a las personas a perder la fe religiosa. El estudio muestra que no hay diferencia en el género (sexo) en cuando al porcentaje de religiosos, pero sí hay una diferencia en cuanto a la edad-es más probable que los científicos jóvenes crean en Dios que los científicos de edad avanzada. En realidad, según sugieren Ecklund y Scheitle, entre los científicos, como en la población general, el factor de predicción más importante para la religiosidad presente en los sujetos es haber sido criado en un hogar donde se valoraban la religión y la práctica religiosa.

Este revelador estudio muestra que no es la evidencia en sí misma la que hace que la gente tenga una visión atea 0 teísta de la existencia. Hay factores que son ajenos al contenido científico y que la ciencia no puede explicar. Este estudio también contradice lo que los Nuevos Ateos condenan: que la religión frena el desarrollo intelectual, científico y no promueve la ciencia. Los sujetos entrevistados en el estudio eran científicos de algu- 
nas de las más prestigiosas universidades de Norteamérica, investigadores con doctorados en varios campos de la ciencia. Para ellos, la creencia en Dios no es incompatible con el desarrollo intelectual. Para muchos de ellos, no hay conflicto inherente entre la ciencia y la fe.

Muchos creemos que la fe, especialmente la cristiana, ofrece un marco intelectual que impulsa la investigación, al mismo tiempo que abre a una narrativa más amplia en la que caben cuestiones que surgen de la ciencia pero que yacen más allá de su capacidad de respuesta. De esta manera se aprecia y valora el mundo natural mucho más porque le encontramos un significado todavía mayor que va más allá de la materia. Esta es la razón por la cual tantos teólogos a lo largo de la historia han encomiado el estudio de las ciencias naturales, afirmando sin timidez una motivación religiosa para el estudio de la naturaleza. La lectura cristiana de la naturaleza no niega nada de lo que es en sí misma, excepto el dogmatismo cientificista y materialista que trata de limitar el amplio significado que se puede percibir en las ciencias naturales. Además de la ciencia, necesitamos adquirir conocimiento de otras fuentes para enriquecer la visión de la realidad de la manera más completa posible. La ciencia es una fuente de conocimiento maravillosa que nos proporciona muchas cosas buenas por medio de la experiencia. Pero hay buenos motivos para pensar que hay una parte de la realidad que no se puede entender o explicar con los métodos de la ciencia.

\section{El conflicto en cuanto a quién tiene la autoridad}

Existe la convicción en ciertos círculos académicos de que de igual manera que la ciencia es capaz de explicar de manera naturalista aspectos de la naturaleza que antes se atribuían a fuerzas misteriosas, la sociedad comprenderá que no es necesario recurrir a un ser divino para intentar explicar el origen y funcionamiento de la naturaleza. Como ya mencionamos anteriormente, esta es la cosmovisión cientificista. En esta línea de pensamiento, en su notable libro La historia del tiempo (1988), el físico teórico y cosmólogo Stephen Hawking afirmó que:

"si descubrimos una teoría completa,
con el tiempo habrá de ser, en sus lí-
neas maestras, comprensible para
todos y no únicamente para unos po-
cos científicos. Entonces todos, filóso-
fos, científicos y la gente corriente, se-
remos capaces de tomar parte en la
discusión de por qué existe el universo
y por qué existimos nosotros. Si en-
contrásemos una respuesta a esto,
sería el triunfo definitivo de la razón
humana, porque entonces conoce-
ríamos el pensamiento de Dios"
(Hawking, 1988, p. 224).

"La ciencia está dando cada vez más respuestas a preguntas que solían ser domino de la religión", afirmó Hawking en una declaración pública en el año 2010 (Citado en Sequeiros, Martínez de la Fe y Prieto Santana, 2010, p. 814). Estas dos declaraciones de Hawking relegan la religión al reino de lo innecesario porque asumen que la ciencia proporciona respuestas precisas a las grandes preguntas, y hasta es capaz de llegar a conocer el pensamiento de Dios. En algunas sociedades 
tecnológicamente avanzadas esta convicción parece ser más penetrante en el mundo académico que en la población general.

A algunos les inquieta la cuestión de quién tiene la autoridad para ofrecer respuestas. El filósofo de la Universidad de Nueva York, Thomas Nagel lo reconoce de esta manera tan sincera:

"Hablo por experiencia, estando fuertemente sujeto a este miedo: quiero que el ateísmo sea verdad y me inquieta el hecho de que algunas de las personas más inteligentes y mejor informadas que conozco son creyentes religiosos. No es solo que no creo en Dios $y$, naturalmente, espero tener razón en mi creencia. ¡Es que espero que no haya Dios! No quiero que haya un Dios; no quiero que el universo sea así. Supongo que este problema de autoridad cósmica no es una condición rara y que es responsable de gran parte del cientificismo y el reduccionismo de nuestro tiempo. Una de las tendencias que apoya es el uso excesivo ridículo de la biología evolutiva para explicar todo sobre la vida humana, incluido todo sobre la mente humana (...) Esta es una situación algo ridícula (...) Es tan irracional que las creencias de uno se vean influenciadas por la esperanza de que Dios no existe como por la esperanza de que Dios sí existe" (Nagel, 1997).

Fijémonos que, al contrario que otros pensadores ateos y materialistas, Nagel se molesta porque la ciencia es la que exige la autoridad total hasta el punto de reclamar que no debe haber Dios. Eso es lo que precisamente desea Nagel: que Dios no exista, y en un ejercicio de sinceridad reconoce que ese deseo es una pos- tura ridícula e irracional. Le molesta la autoridad divina.

El rechazo de la autoridad divina es aún más intenso en las palabras del investigador en genética Richard Lewontin, quien afirma que:

"Nuestra voluntad de aceptar afirmaciones científicas contrarias al sentido común es la clave para comprender la lucha real entre la ciencia y lo sobrenatural. Nos ponemos del lado de la ciencia a pesar de lo patentemente absurdo que son algunos de sus constructos, a pesar del incumplimiento de muchas de sus extravagantes promesas de salud y vida, a pesar de la tolerancia de la comunidad científica a las historias sin fundamento, porque tenemos un compromiso previo, un compromiso con el materialismo. No es que los métodos e instituciones de la ciencia nos obliguen de alguna manera a aceptar una explicación material del mundo fenoménico, sino que, por el contrario, estamos obligados por nuestra adherencia a priori a las causas materiales para crear un aparato de investigación y un conjunto de conceptos que producen explicaciones materiales, no importa cuán contradictorio sea, no importa cuán desconcertante para los no iniciados. Además, ese materialismo es absoluto, ya que no podemos permitir un pie divino en la puerta. El eminente erudito de Kant Lewis Beck solía decir que cualquiera que pudiera creer en Dios podía creer en cualquier cosa. Apelar a una deidad omnipotente es permitir que en cualquier momento se rompan las regularidades de la naturaleza, que los milagros pueden suceder" (Lewontin, 1997, p. 31). 
Este tipo de pensamiento es intolerante e irracional. Lewontin quiere dejar a la ciencia absolutamente libre de religión, aun reconociendo lo absurdo que puede llegar la ciencia con sus afirmaciones. Y lo grave es que no es la ciencia la que le obliga a ser materialista, sino su filosofía personal hacia la religión. Lewontin comienza su declaración hablando de "la lucha real entre la ciencia y lo sobrenatural", pero después afirma que no es la ciencia la que le obliga a ser materialista, dejando implícito que no hay tal lucha. Lewontin se siente obligado a aceptar la autoridad de la ciencia, aunque ella conduzca a conclusiones absurdas. Su materialismo es absoluto, no permitiendo siquiera que Dios ponga el pie en la puerta. Uno recuerda la imagen que resulta de la frase de Jesús en Apocalipsis 3:20: "Yo estoy a la puerta y llamo; si alguno oye mi voz y abre la puerta, entraré a él y cenaré con él y él conmigo". No parece que Lewontin fuera a invitar a cenar a la Divinidad.

La postura de Lewontin no es exagerada en muchos ámbitos académicos como nosotros hemos podido comprobar en nuestras investigaciones. La ciencia ha declarado que ella es la única autoridad para establecer la verdad y decir cómo debe ser la vida de las personas y la gestión y explicación del mundo natural, y no hay lugar ni para que lo divino pueda entrar en la conversación.

Como Lewontin, se mantienen focos intelectuales que sostienen que la ciencia naturalista es $-y$ debe sersuficiente para explicar el universo, la vida, y el origen, naturaleza y emociones del ser humano. Como hemos indicado al comienzo, estos pensadores se aferran a una visión cientificista y materialista de la ciencia: la única fuente de verdad es la que procede de métodos empíricos estudiando lo único que existe, que es la materia. Las leyes de la física son adecuadas y suficientes en sí mismas para explicar el origen y funcionamiento del universo, y no hay nada más. Esta es la cosmovisión de los físicos Stephen Hawking y Leonard Mlodinow en su libro El gran diseño. Estos autores declaran que "la filosofía está muerta", dejando el campo libre para que los científicos se conviertan en los "portadores de la antorcha del descubrimiento en nuestra búsqueda del conocimiento" (Hawking y Mlodinow, 2010, p. 5). Por otro lado, se puede argumentar que el hecho de que muchos científicos hayan comenzado a cuestionar el darwinismo a partir de la ciencia, y que se sigue hablando de la narrativa bíblica de la creación, muestra que el asunto no está "muerto" de ninguna manera. En la cosmovisión de Hawking uno tiene que elegir entre Dios y las leyes de la física, como si ambas no pudieran ser ciertas o válidas, o estuvieran en conflicto mutuo. De esa manera, la idea del conflicto entre ciencia y fe se mantiene en aquellos que piensan que la ciencia reina por encima de toda otra forma de pensamiento, y que en realidad no existe otra forma válida de entender el mundo. Es un conflicto de autoridad, no de evidencia contra evidencia.

Nosotros mantenemos que no hay conflicto inherente entre la ciencia y la fe, más allá de lo que algunos científicos se empeñan en crear con sus posturas absolutistas. Respondemos a los que todavía sostienen esta forma de cientificismo que es difícil de ver cómo las leyes de la física pueden proporcionar una explicación completa del universo y la vida. Después de todo, por sí mismas las leyes de la física no crean nada; son una descripción de 
cómo funciona el mundo bajo ciertas condiciones, pero no de cómo surgió el mundo. Las leyes no son causas, sino descripciones matemáticas de lo que regula el funcionamiento del mundo. Lo que pretenden Hawking y Mlodinow es convencernos de que las leyes hacen que surjan las entidades existentes (estrellas, agua, rocas, mitocondrias, altruismo, etc.). Pero no es así. Las leyes de la física no pueden decirnos de dónde vino el universo, solo que está allí. Una cosa es la causa y otra es la explicación. Además, ¿de dónde vinieron esas causas en primer lugar?

Además, Hawking, Mlodinow y otros con las mismas ideas necesitan recordar que la ciencia tiene una enorme capacidad de explicación, pero sin embargo falla a la hora de explicar los profundos anhelos y preguntas de la humanidad. No tiene autoridad en ese campo. Las preguntas que realmente importan acaban teniendo su esfera fuera de la ciencia, no porque haya nada en particular errado en la ciencia sino porque la ciencia tiene sus límites. El filósofo español Ortega y Gasset lo dijo de esta manera elocuente: "la verdad científica se caracteriza por su precisión y la certidumbre de sus predicciones. Pero la ciencia alcanza estas admirables cualidades a expensas de mantenerse en el nivel de asuntos secundarios, dejando las preguntas fundamentales $y$ decisivas sin tocar" (Ortega y Gasset, 1967, p. 259). Para Ortega y Gasset la gran virtud intelectual de la ciencia es que conoce sus límites-solo responde las preguntas que sabe que puede responder en base a la evidencia. Nos parece que Hawking y otros cientificistas no se dan cuenta de ello.

Susan Wolf positivamente afirma que la religión es ahora una de las fuentes más importantes de significado, valor y autoridad en nuestra cultura (Wolf, 2010). Como seres humanos necesitamos algo que sostenga nuestra razón y nuestra experiencia, nuestras mentes y corazones, nuestros sentimientos y razonamientos. Algo más que el puro racionalismo materialista, algo que ilumine nuestras vidas para ser un todo. Para conseguir esa holística, el ser humano necesita la religión, no como un amuleto, sino como una autoridad que forma parte de nuestra existencia vital y se extiende a los diversos aspectos de ella. Esto es algo que el escritor británico Salman Rushdie elegantemente afirmó en su discurso de 1990 en la Universidad de Cambridge, donde dijo que la religión satisface tres tipos de necesidades que el materialismo secular no es capaz. Primero, nos permite articular nuestro sentido de admiración y asombro, en parte al mostrarnos la grandeza de la vida y en parte por decirnos que somos especiales. En segundo lugar, nos proporciona 'respuestas a lo incontestable', yendo a las preguntas profundas que nos dejan perplejos. En tercer lugar, nos ofrece un marco moral dentro del que podemos vivir vidas agradables (Rushdie, 1990, pp. 8-9).

\section{El conflicto en cuanto a la mo- ralidad humana}

La biología evolucionista no sabe cómo explicar el origen y fundamento de la moralidad, pero evidentemente debe haberse originado por la selección natural actuando sobre las redes genómicas en interacción con el ambiente natural y social-es decir, un origen naturalista para la moralidad. Algunos evolucionistas van más allá, como la filósofa británica Catherine Wilson, quien afirma que: 
"Mi argumento central es que las ciencias biológicas pueden contribuir al progreso moral-no sólo en cuanto a la explicación de los orígenes y la formación de las actitudes y disposiciones morales- pero eso es posible sólo si se trabaja para disipar los mitos y supersticiones que sostienen las relaciones sociales opresivas" (Wilson, 2010).

La evolución, dice Wilson, es capaz de explicar la moralidad, pero solo si elimina la religión primero. Este conflicto ya surgió con Darwin, quien creía que la agonística interacción entre clanes y tribus en la prehistoria había moldeado el carácter humano, formando las virtudes del coraje, simpatía, altruismo y fidelidad, obteniendo así una ventaja evolutiva. El problema de cómo explicamos el sentido moral dentro del escenario evolutivo lo trata Darwin en los capítulos 4 y 5 de su libro El origen del hombre (1871), quien postula que "un animal cualquiera, dotado de instintos sociales pronunciados, adquiriría inevitablemente un sentido moral o una conciencia, tan pronto como sus facultades intelectuales se hubieren desarrollado tan bien, o casi tan bien como en el hombre" (Darwin, 1971, p. 49). Herbert Spencer, uno de los primeros defensores de Darwin, fue un defensor entusiasta de la ética evolucionista (Farber, 1994). Según este modelo evolucionista, el origen de la moralidad no está en la intervención divina, sino en las pautas de comportamiento determinadas por la selección natural y la adaptación. No es necesario que nosotros recordemos que esta idea era (y es) puramente especulativa, y que Darwin (y todos sus sucesores) no aportó ninguna evidencia para este origen naturalista/cultural de la moralidad. La presentación de las ideas de Darwin puso en alerta a los cristianos, quienes percibieron que la evolución destruiría los conceptos de moralidad. Los pensadores opinaban que estos desarrollos iban a cambiar todo concepto relevante en nuestra manera de vernos, conceptos tales como racionalidad, conciencia, moralidad, percepción del mal, justicia social, culpabilidad, significado de la vida, egoísmo, etc. Durante mucho tiempo los evolucionistas respondieron diciendo que el Darwinismo no comprometía la moralidad. Se desmarcaron de un evidente conflicto entre la presuposición materialista de que lo único que existe es la materia y la energía y la obvia existencia de la inmaterial moralidad. Sin embargo, esto ha cambiado y en los últimos años los evolucionistas ya están afirmando que la teoría socava las bases de la moralidad.

La literatura especializada contemporánea abunda en modelos evolucionistas que tratan de explicar el origen de la moralidad (Ayala, 1987; de Waal, Smith Churchland, Pievani, y Parmigiani, 2014; Goodenough y Deacon, 2003; Joyce, 2006; Katz, 2000; Krebs, 2011). Por ejemplo, algunos evolucionistas afirman que la biología puede dar cuenta de la moralidad y que el comportamiento moral no tiene nada que ver con la religión, sino que depende fundamentalmente de la función cerebral. El comportamiento se explica partiendo de la fisiología en vez de procesos psicológicos (Monterosso, Royzman y Schwartz, 2005). La premisa fundamental de estos modelos es que la moralidad evolucionó de manera biológica a partir de los primates como producto derivado de la selección natural. En esa línea están las afirmaciones del profesor de psicología de la Universidad de Washington David Barash, "Cuanto más sabemos de evolución, más inevitable es la 
conclusión de que los seres vivos, incluyendo los seres humanos, son productos de un proceso natural totalmente amoral, sin indicación de un creador benevolente controlador" (Barash, 2014). Además indica que esa idea es la que enseña en sus clases cada año y que muchos estudiantes se preocupan por cómo pueden reconciliar sus creencias con la ciencia evolucionista. No nos extraña que los estudiantes tengan esa reacción, la cual surge del claro conflicto epistemológico que se presenta en sus mentes. En esta cosmovisión evolucionista, el comportamiento moral humano es simplemente la forma en que la naturaleza resuelve ciertas situaciones, y ese comportamiento puede cambiar si la situación cambia, pero no tiene nada que ver con el bien o el mal. La culpa no existe, solamente el sentimiento de culpa. Los juicios sobre la moralidad son solamente expresiones de preferencia. No hay actos justos o malvados, bondad ni maldad, y tampoco obligaciones morales objetivas. Es solo una cuestión de gusto. A su vez, el arrepentimiento no es la aceptación de que hicimos algo mal, sino la concesión de un instinto (de naturaleza animal) a otro. La dignidad, como cualquier otro valor, no es una propiedad objetiva de nadie. Finalmente, no existe un código moral absoluto que nos ayude a determinar qué comportamientos morales son superiores a los demás. Las personas sienten que deben obedecer un instinto en lugar de otro, pero no pueden establecer que deben obedecer un instinto sobre el otro. El motivo para esto es que ningún juicio moral es de mayor valor o tiene una autoridad moral mayor que los demás.

Como se ha visto, el desarrollo de la biología evolucionista ha tenido profundas implicaciones en la religión, la moralidad y la manera de entender al ser humano en general, pero la revolución darwinista no ha sido completa porque no ha abrazado todas sus implicaciones morales y religiosas. Si aceptamos la evolución materialista, tendremos que asentir con Richard D. Alexander en que los desarrollos recientes tienen tal impacto que "tendremos que empezar todo de nuevo a describirnos y comprendernos en términos ajenos a nuestras intuiciones" (Alexander, 1987, p. 3). Queda claro que, si adoptamos los desarrollos de la biología evolucionista, nuestros conceptos religiosos (especialmente aquellos derivados del cristianismo) se van a ver seriamente afectados, porque el evolucionismo entendido como materialismo está en conflicto con los valores religiosos cristianos.

En este sentido, las afirmaciones de los Nuevos Ateos y los posmodernos de que la moralidad no existe o que es relativa y variable se puede explicar en términos de una ciega huida hacia la negación misma. A menudo los historiadores señalan que los orígenes del Nuevo Ateísmo reflejan un deseo humano de hacer cualquier cosa que deseen, en lugar de vivir y funcionar dentro de un marco moral divinamente instaurado (Buckley, 1987). Lo afirma abiertamente el filósofo británico Alister McGrath: "El deseo de tener autonomía humana total se expandió a un deseo de eliminar los obstáculos percibidos para tal libertad-incluyendo la noción de Dios" (McGrath, 2017, pp. 80-81).

\section{El conflicto en cuanto al propó- sito de la vida humana}

Uno de las críticas expresadas a los evolucionistas y materialistas es que para ellos no hay diseño, no hay propósito, y la moralidad humana es fruto de convenciones adecuadas para un tiempo y espa- 
cio, no derivadas de un espíritu divino. Dentro del marco narrativo sobre los orígenes, éste es quizá el punto de conflicto más serio entre la ciencia y la religión. En esa línea está la reflexión del teólogo John F. Caught, quien cree que si los biólogos evolucionistas están en lo cierto entonces el conflicto es tan serio que "aunque la teología pueda acomodar muchas ideas científicas diferentes, no puede estar conforme con la noción inherente de un cosmos sin propósito" porque tal idea es central para los intereses teológicos y religiosos (Haught, 2008, p. 126).

En la Escritura cristiana hay un claro mensaje de que el ser humano fue creado a la imagen y semejanza de Dios (Gn 1:26-27) y que su vida tiene un propósito. Ese propósito es multifacético e incluye, entre otros aspectos, dar gloria a Dios (Is 43:7), el servicio a Dios (1Sam 12:24), y el trabajo útil (Gn 1:28; 2:8, 9, 15). La Escritura deja claro que Dios creó la naturaleza con propósitos y funciones determinadas y obviamente descifrables. Jesús dedicó sus parábolas para ilustrar el propósito de la existencia humana: amarnos unos a otros, servir al débil, ser generoso, respetar las normas del estado civil, ser un buen administrador de los bienes materiales, ejemplificar la virtud del perdón, y conectar con Dios como una parra se conecta a la viña dando abundante fruto (Jn 15:1-17). Pablo afirma que Dios le "apartó" desde el vientre de su madre para el propósito de predicar entre los gentiles (Ga. 1:15-16).

Es innegable que la vida del ser humano muestra propósito en la vida. La psicología moderna señala a la existencia universal de un significado y propósito inherente en los seres humanos. El propósito también es claramente observable en el mundo natural, siendo de hecho el objeto de estudio en muchas iniciativas humanas. ¿Cuáles han sido las reacciones a esta observación entre los científicos?

Se dice que el ser humano es teleológico, es decir, con un propósito, función u objetivo. El observador casual y muchos científicos han notado como en la naturaleza se observan evidencias de propósito y diseño para una función, desde los 'comportamientos químicos' de las células al crecimiento de las plantas, a las acciones de los diversos animales. De hecho, la evidencia de propósito es casi omnipresente. La actividad con propósito o teleológica no una simple descripción de los fenómenos observados, sino un rasgo inherente en los seres vivos en general. El bioquímico y premio Nobel Jacques Monod describió este propósito como:

"...una de las características comunes fundamentales a todos los seres vivos sin excepción: se ser objetos dotados de un propósito o proyecto que al mismo tiempo muestran en su estructura y ejecutan a través de sus acciones... se debe reconocer como esencial a la misma definición de seres vivos" (Monod, 1971, p. 20).

Otros han tomado una posición opuesta, negando categóricamente la existencia de propósito en los seres vivientes. "No tiene sentido preguntarse cuál es el propósito de nuestra existencia", afirma la filósofa británica Catherine Wilson, "nuestra especie está aquí debido a que un número de eventos improbables y únicos convergieron para traer nuestra especie a escena, y sólo existen los propósitos particulares que establecemos para nosotros mismos" (Wilson, 2010, p. 275). El paleontólogo de Harvard Stephen Jay Gould afirmó que "Darwin argumenta que la evolución 
no tiene un propósito. Los individuos luchan para aumentar la representación de sus genes en generaciones futuras, y eso es todo" (Gould, 1977, p. 12). "Somos el resultado accidental de un proceso no planeado (...) el frágil resultado de una enorme concatenación de improbabilidades, no el resultado predecible de algún proceso definitivo" (Gould, 1983, pp. 101-102). En la misma línea de razonamiento, el biólogo Richard Dawkins mantiene que:

"El universo que observamos tiene precisamente las propiedades que esperaríamos si no hay, en el fondo, ningún diseño, ningún propósito, ni mal ni bien, nada sino indiferencia ciega e inmisericordia(...)el ADN ni sabe ni le importa. El ADN solo es. $Y$ nosotros bailamos al son de su música" (Dawkins, 1995).

En la misma pauta de indiferencia, el paleontólogo George Gaylord Simpson afirma que "El hombre es el resultado de procesos naturales sin propósito que no lo tuvieron a él en mente" (Simpson, 1967, p. 345).

Un tercer grupo de pensadores ha adoptado una postura intermedia, indicando que el propósito es solo aparente, y que no nos debemos dejar engañar porque es solo una ilusión. La Stanford Encyclopedia of Philosphy, en su artículo titulado Teleological Notions in Biology afirma que:

"La apariencia manifiesta de función y propósito en los sistemas vivos es responsable de la prevalencia de explicaciones aparentemente teleológicas de la estructura y el comportamiento de los organismos en la biología. Aunque la atribución de la función y el propósito a los sistemas vi- vos es una práctica antigua, las nociones teleológicas se consideran en gran medida imposibles de eliminar de las ciencias biológicas modernas, como la biología evolutiva, la genética, la medicina, la etología y la psiquiatría, porque desempeñan un importante papel explicativo" (Allen y Neal, 2019).

La idea expresada es que el propósito es aparente nada más. Esta idea no es nueva, y Julian Huxley (1887-1975), biólogo evolutivo británico que acuñó el término Síntesis Moderna para referirse al neodarwinismo, ya de la atribuyó indirectamente a Darwin,

"Fue uno de los grandes méritos de Darwin mismo mostrar que el propósito de la estructura y función orgánica eran solo aparentes. La teleología de la adaptación es una pseudoteleología, que se puede explicar por medio de buenos principios mecánicos, sin la intervención de propósito, consciente o inconsciente, bien de parte del organismo o de un poder exterior" (Huxley, 1942, p. 412).

Y más recientemente, Richard Dawkins, el hombre que más vehementemente abandera el Nuevo Ateísmo, nos avisa de que esa ilusión de propósito puede llegar a cautivarnos y, por tanto, hemos de estar alerta: "Tan abrumadora es la apariencia de un deliberado diseño que, incluso en esta época darwiniana cuando sabemos 'mejor', todavía nos resulta difícil, de hecho, aburridamente pedante, abstenerse del lenguaje teleológico cuando hablamos de adaptación". Y sin embargo, "la teoría de la selección natural proporciona un relato mecanicista y causal de cómo los seres vivos llegaron a verse como si hubie- 
ran sido diseñados para un propósito" (Dawkins, 1982).

Estas tres declaraciones tratan de rebajar las expectativas de admisión de propósito en la naturaleza. Insisten en que la teleología, o propósito es sólo aparente, que da una falsa impresión de serlo, pero no lo es. Que es como si, pero no es. Tal como reconoce Dawkins, el lenguaje teleológico es común y extenso en toda la literatura científica actual. La razón, tal como Allen y Neal admiten, es que es inevitable e imposible de eliminar. Una expresión común en biociencias es "morfología funcional", aplicándose en particular en nuestro campo de investigaciones (paleontología) a la interpretación de funciones, adaptaciones, propósito de órganos, estructuras óseas, y otras estructuras de los fósiles, partiendo de la forma o la organización. Uno de los tipos de fósiles que nosotros estudiamos es el llamado icnofósiles, que no son restos orgánicos fosilizados, sino evidencias de su presencia o actividad (pisadas, marcas de dientes, galerías, excavaciones, etc.). El estudio de la forma, tamaño y relleno de las galerías fósiles en un corte de rocas nos permite especular sobre la función o propósito de la galería cuando el animal construyó la galería. De ese modo examinamos las galerías fósiles y determinamos su función para el organismo: pudo ser una galería que funcionara como escondite, o como lugar de nidación, o como vía de escape después de un enterramiento rápido por sedimento, o como resultado de la alimentación (el animal ingiriendo sedimento a medida que se mueve). Inferimos función y propósito a partir de la forma y otras características. No sólo se asume que hubo un propósito en el animal al excavar inicialmente la galería, sino que el paleontólogo la estudia con la certeza de que lo hubo. No hay duda. No interpretamos la función o el propósito de la estructura como si, sino como que es.

Tenemos, por tanto, al menos tres visiones predominantes: la visión de la fe cristiana predica que existe propósito en la naturaleza y, en especial, el ser humano, y que ese propósito fue infundido por la Divinidad; la visión materialista afirma que no hay propósito en absoluto en la naturaleza; y la tercera visión sostiene que el propósito es aparente, pero es atribuible a fuerzas moleculares, el resultado de un programa genético interno que actúa mecánicamente sobre nosotros y sobre el que no tenemos ni consciencia ni control. Cada una de estas tres visiones a su vez da una visión completamente diferente del mundo natural y del valor y lugar del ser humano en la existencia del mundo, y ello es una fuente de interpretaciones conflictivas entre la ciencia y la fe. Insistimos que la ciencia y la fe en sí mimas no están en conflicto, sino las interpretaciones que resultan de adoptar cosmovisiones diferentes sobre la vida y el lugar del ser humano en el esquema de este universo.

Dentro de esta fuente de conflicto epistemológico, existe un aspecto más del que surgen profundas divisiones, aquí incluyendo las discordias dentro del mismo campo científico evolucionista: ¿Cuál es el origen del propósito? Ya no hablamos de si existe o no, si no de dónde proviene. Para los teístas, el origen es claro: Dios lo diseñó. Para el evolucionista, aquel que acepta la existencia de algún tipo de propósito o significado, ha de ser un agente interno: la selección natural o un programa genético inherente en las células. En esta última línea de pensamiento está el renombrado biólogo evolucionista Ernst Mayr, quien admitió que "El desarro- 
Ilo o comportamiento de un individuo muestra propósito; la selección natural definitivamente no", y que "La acción con propósito de un individuo, en la medida en que se basa en las propiedades de un código genético, no tiene más ni menos propósito que las acciones de una computadora que ya sido programada para responder apropiadamente a las diversas órdenes exteriores" (Mayr, 1972, p. 31). Para Mayr, este comportamiento que muestra propósito es el resultado de un "mecanismo puramente mecánico" que ya ha sido previamente instalado en los seres vivos, como el software de una computadora. Mayr no indica cómo o quién ha podido instalar ese software. Ni tampoco Mayr ni ningún científico han mostrado cómo el código genético $u$ otro mecanismo puramente mecánico puede determinar el comportamiento con propósito que vemos en los animales y el ser humano. La idea de que un código bioquímico operacionalmente similar al código de una computadora explica el comportamiento con propósito del ser humano es persistente entre muchos científicos, pero nadie ha encontrado evidencia de ello ni siquiera pistas de cómo pudiera funcionar. Ese programa "no se halla en ningún sitio" y "no es una entidad biológica existente" (Moss, 1992, p. 335). De hecho, los descubrimientos de la genética de los últimos veinte años van en sentido opuesto a ese postulado, mostrando que la compleja bioquímica del ADN y las células en general van mucho más allá de la estricta manifestación de la información contenida en un código.

Este es un tema donde los modelos naturalistas se estrellan: ¿cómo explicar algo inmaterial partiendo de la sola acción química de las moléculas? ¿Cómo explicar el propósito, la direccionalidad en la vida-la característica fundamental de la vida misma, y que le diferencia de la materia no viva-partiendo de interacciones moleculares? El propósito es lo que define lo que llamamos viviente. No se puede ignorar, minimizar o pretender que es solo aparente. Es lo que define al ser humano. El ser humano es consciente de si mismo, de su existencia, su funcionamiento, su significado en el más amplio escenario vital. Nadie puede afirmar que esa conciencia es el resultado exclusivo de las interacciones químicas en las neuronas o el funcionamiento de los órganos sensoriales. Nosotros no vemos los objetos en movimiento a nuestro alrededor y observamos puntos erráticos o caóticos procesados de manera molecular, sino acciones coherentes e inteligentes que nos permiten diferenciarlas de otras y tomar decisiones. "Lo único que puede darnos un mundo es alguna forma de conciencia perceptiva", dice Stephen Talbott (2017, p. 69). La conciencia de la existencia propia y de la existencia de propósito es inherente a los seres humanos, y no parece surgir puramente de la actividad química cerebral. Las acciones de los seres vivos conscientes, por muy pequeñas que sean, son significativas porque producen un final significativo, a partir de lo cual no podemos evitar concluir que hay un final intencionado, con propósito y función.

La idea de un comportamiento teleológico dentro de un mundo con significado no es del agrado de los científicos comprometidos con el naturalismo o materialismo. Este desagrado parece resultar de la faceta de existencia de conciencia inherente, lo cual, por otro lado, es innegable. Pensemos en los procesos de desarrollo y funcionamiento de la célula a medida que crece y se divide. Toda la maquinaria bioquímica trabaja hacia un objetivo, direccionando sus reacciones e inter- 
acciones moleculares hacia un propósito evidente. Nada ocurre al azar o sin propósito dentro de la célula. Y aunque la célula no tiene mente o conciencia, sin embargo, posee una capacidad inherente de cumplir un propósito. ¿De dónde procede esa capacidad inherente de propósito? Las moléculas no pueden aportarla. Las moléculas son sólo moléculas, al igual que un automóvil en sí mismo no tiene un propósito inherente más allá de sus componentes materiales-el propósito deriva de lo que el ingeniero inteligente ha dispuesto para hacerlo funcionar de una manera y no de otra. El automóvil no tiene conciencia de su futuro, no trabaja para organizarlo, cambiarlo, definirlo o mejorarlo; en cambio los seres humanos somos conscientes de ello y es nuestra principal ocupación, somos organismos orientados hacia el futuro. Eso no deriva de la actividad química. Las partículas atómicas o las moléculas como tal no pueden determinar nada y ni siquiera reordenarse sin un plan de acción externo. Incluso la forma de vida más sencilla parece tener una direccionalidad hacia hacer algo, como si estuviera tratando de alcanzar un propósito-alimentarse, reproducirse, refugiarse, cortejar, cuidar de la prole, etc. Y si dotamos a las moléculas u órganos de propiedades inmateriales-como es común en la literatura científica-como "tendencias", "adaptación", y demás, estamos otorgando a la materia propiedades inherentes que son precisamente las que queremos explicar en primer lugar. Les damos a las moléculas y rutas moleculares las propiedades de "auto ensamblarse", "regular", "controlar", "adaptarse", "modificar" etc.-propiedades teleológicas, que implican significado y propósito-que son precisamente aquello que necesitamos explicar en primer término. Se convierte en un razonamiento circular. Uno ha de presuponer propósito, dirección y significado en la materia a fin de explicar propósito, dirección y significado en la materia biológica. Por ello, resulta inevitable que tal propósito, dirección y significado procedan de un agente conocedor externo.

En este punto hemos de mencionar una preocupante diferencia entre las publicaciones profesionales en sociología, psicología y filosofía, y los libros de texto de casi cualquier materia. La literatura profesional en los campos mencionamos primeramente es extremadamente abundante, con numerosas publicaciones que indican que los seres humanos somos más que seres biológicos-somos seres psíquicos que vivimos mejor en este complejo y difícil mundo si somos capaces de encontrar nuestro significado y valor dentro de nuestras vidas (por ejemplo Wong, 2013). Los seres humanos estamos hechos de tal manera que buscamos algo más profundo de lo que puede hallarse solamente por la exploración del mundo empírico. En los libros de texto, sin embargo, no encontramos mención alguna de la existencia de propósito en la naturaleza viviente- 0 del significado inherente en el propósito. Parece como si el referirse a la existencia de propósito en la vida fuese entrar en el mundo de la mística, algo que no es parte de la metodología y ámbito de la ciencia. Las descripciones científicas están generalmente limpias o vacías de afirmaciones o incluso insinuaciones de propósito 0 inteligencia activa restringiéndose exclusivamente a los "hechos físicos observables". ¿Por qué algo tan obvio como la existencia de propósito en la naturaleza viviente $y$, en especial, los seres humanos, no puede formar parte del lenguaje de los biólogos evolucionistas? 
Es una herencia de Darwin. Darwin nos dejó una visión empobrecida de la naturaleza humana, su lugar en el mundo y su propósito. El desafío que presenta la teoría de la evolución pone en peligro la creencia religiosa de que hay un propósito para la existencia de la vida humana en particular, y por tanto la gente debería rechazar tal creencia o incluso abandonar su religión completamente. Es evidente que esta cosmovisión materialista está en claro conflicto con la religión, especialmente la cristiana, que atribuye propósito y sentido a la vida humana más allá de la existencia puramente orgánica. Hemos de reiterar aquí que es la cosmovisión materialista no la evidencia científica, la que genera conflicto.

Necesitamos algo más que la ciencia para obtener sentido para nuestras vidas. Las ciencias naturales solo pueden darnos una guía parcial sobre cómo funciona el ser humano y el resto de los organismos, pero no puede conducirnos a las respuestas vitales de la existencia, menos aún sobre el significado de tal existencia.

\section{Llegando a la fe desde la cien- cia}

Las reflexiones anteriores nos llevan a pensar que existe cierta polarización en los pensadores científicos contemporáneos. Recordemos a Lewontin: no se puede permitir que Dios ponga un pie en la puerta. Por un lado, el empiricismo radical del cientificismo mantiene a sus seguidores sujetos al materialismo: la materia y energía son todo lo que existe, es fútil tratar de explicar el mundo por medio de agentes sobrenaturales. El darwinismo es suficiente para explicar el senti- do de la vida biológica. La religión no es más que una narrativa conflictiva que debe evitarse en la práctica académica. Por otro lado, hay destacados personajes de la ciencia y la filosofía que defienden la idea de que, aunque el darwinismo ha introducido conflicto ideológico entre la ciencia y la religión, ello no significa que exista un conflicto entre ciencia y religión como dominios de conocimiento. De hecho, algunos afirman positivamente que la ciencia todavía contiene amplio espacio para Dios. Por ejemplo, Christian de Duve, Premio Nobel en 1974 y biólogo molecular de la Universidad de Lovaina en Bélgica, dice: "Muchos de mis amigos científicos son ateos acérrimos, pero no hay razón para que la ciencia aplique o establezca el ateísmo. La incredulidad es sólo una de las muchas visiones personales posibles" (citado en Easterbrook, 1997). Joshua Lederberg, biólogo evolutivo de la Universidad Rockefeller en la ciudad de Nueva York y ganador del Premio Nobel en 1958, dice, "Nada hasta el momento desmiente lo divino. Lo que es incontrovertible es que un impulso religioso guía nuestros motivos para sostener la investigación científica. Más allá de eso, todo es especulación" (Easterbrook, 1997). Para Lederberg la religión no sólo no es contraria a la ciencia, sino que además guía los motivos para llevar a cabo trabajo científico.

Este era el fundamento filosófico inherente en la ciencia de los primeros dieciocho siglos de la era cristiana: la naturaleza refleja las cualidades de Dios-es ordenada, predecible, estable, constante y uniforme-cualidades que no solo hacen posible su comprensión, sino que también invitan a su estudio. Esas cualidades son lo que llamamos leyes de la naturaleza. El cristiano siente una gran apreciación por estas cualidades. Dios hizo el mundo de 
manera que tiene sentido, e hizo los seres humanos de manera que pueden entender el universo que tiene sentido. A su vez, la comprensión del universo puede llevarnos de nuevo a la idea de Dios y su actividad en la naturaleza.

Recordemos el ejemplo ya mencionado del desarrollo de las ideas sobre el origen el universo. Cuando el astrofísico y astrónomo católico Georges Lemaitre propuso por primera vez en 1927 que el universo comenzó con una detonación de un "átomo primordial", una idea que más tarde se llamó Big Bang, muchos científicos se opusieron a la teoría en parte porque parecía derivar de la historia del inicio del universo según el Génesis. Además, esa teoría parecía apoyar la idea de un origen sobrenatural por un ser superior. En la actualidad, muchos teólogos aceptan la teoría del Big Bang porque se dan cuenta de sus implicaciones espirituales, y de igual manera muchos científicos las contemplan abiertamente. Los científicos se han dado cuenta de que la existencia de la vida depende de las condiciones iniciales del universo. La vida tal como la conocemos depende de manera estrecha de una serie de leyes naturales-varias docenas de constantes físicas que gobiernan el universo de manera estable. Una ligerísima variación en el valor de esas constantes alteraría el universo de tal forma que sería inestable y la vida no sería posible (Davis, 2006; Rees, 2000). Es lo que se llama el ajuste fino del universo. El hecho de que el universo presente muchos aspectos que permiten la vida en la Tierra ha llevado a muchos científicos a especular que alguna influencia divina debe estar presente en el origen y funcionamiento de la maquinaria universal, de manera indirecta aludiendo a la idea de creación bíblica.
Como dijimos al comienzo de este artículo, estos autores a menudo escuchan la afirmación "no se puede ser cristiano y científico a la vez", o "para ser un científico de verdad no se puede creer en la religión", como si la práctica de la ciencia inevitablemente expulsara a Dios del pensamiento y análisis. Se habla muy poco de los científicos, filósofos y pensadores que partiendo de la ciencia han llegado a la fe. Cuanto más se explora en los secretos del universo y la biología más se esperaría que los científicos vieran a Dios como fuera de lugar. Pero no es así para todos. De hecho, lo contrario está ocurriendo: muchos científicos están encontrando a Dios partiendo de la ciencia.

El astrónomo Allan Sandage (1926-2010), por ejemplo, pasó su vida profesional mirando por telescopios desde Chile a California buscando pistas sobre el origen del universo. Después de mantenerse en el ateísmo durante cincuenta años, Sandage llegó a desanimarse de responder a las preguntas fundamentales de su ciencia partiendo solamente de la razón. "Fue mi ciencia la que me condujo a la conclusión de que el mundo es mucho más complicado de lo que se puede explicar por la ciencia. Es solo a través de lo sobrenatural que puedo entender el misterio de la existencia" (citado en Begley y Westley, 1998). John Polkinghorne (1930), quien tuvo una distinguida carrera como físico en la Universidad de Cambridge y pasó a ser sacerdote anglicano en 1982, cree que el ajuste fino de las leyes naturales nos empuja a pensar que el universo no llegó a existir porque sí, sino porque debe haber un propósito detrás. Charles Townes (1915-2015), físico que compartió el Premio Nobel en 1964 por descubrir los principios del laser, fue más allá: "Muchos tienen el sentimiento de que de alguna ma- 
nera una inteligencia debe estar involucrada en las leyes del universo" (Begley y Westley, 1998). En otra ocasión Townes abiertamente declaró que "Creo en la existencia de Dios basándome en la intuición, las observaciones, la lógica y también el conocimiento científico" (Begley y Westley, 1998). Francis Collins (1950-), biólogo genético, exdirector del proyecto Genoma Humano y actual director del National Institutes of Health de EEUU, es un defensor de que la ciencia y la religión no están en conflicto. En su libro ¿Cómo habla Dios? El lenguaje científico de la fe, Collins explica cómo su análisis de las evidencias a favor y en contra de Dios le llevaron a aceptar el cristianismo sin renunciar a su carrera científica (Collins, 2016). Mencionamos las creencias religiosas de estos destacados científicos no para mostrar que la mayoría de los científicos contemporáneos son teístas, sino para desafiar la popular imagen académica contemporánea de que no se puede ser un cualificado investigador $y$ un creyente a la vez porque la ciencia y la fe son antagonistas. Los autores de este artículo son testimonio viviente de ello.

Como hemos indicado anteriormente, la cosmología del Big Bang, que parecía explicar el origen del universo de manera materialista, y el descubrimiento del ajuste fino del universo han llevado a algunos científicos a pensar que hay un diseño y un propósito detrás del cosmos. Los físicos hablan de signos de que el universo está hecho con el propósito de la vida, e incluso con el ser humano como propósito. De manera a similar los descubrimientos en la bioquímica, la biología molecular y la célula, han llevado a diversos investigadores a creer que debe haber una inteligencia superior detrás de las complicadas estructuras biológicas. Los científicos que antes creían que la ciencia había "matado" a Dios ahora sostienen que la ciencia restaura la fe.

La comunidad intelectual en general está adoptando la idea de que el conflicto inherente es un concepto desfasado e ineficaz, y se está beneficiando de una visión más rica de la realidad que resulta de permitir que la ciencia y la fe interaccionen, dialoguen y se informen una a la otra de manera constructiva. No pretendemos tornar la ciencia en religión o viceversa. La religión es religión, y la ciencia es ciencia, cada una con su metodología y alcance, pero ninguna de las dos debe trabajar aislada de la otra. Lo que nosotros proponemos es que hablen la una a la otra sin roles de autoridad prejuiciosamente establecidos a priori, que colaboren hacia el alcance de mejores modelos para una explicación más rica de la realidad. Quizá en el proceso el lector halle el mismo sentido de satisfacción y realización personal que nosotros encontramos al explorar la fascinante realidad natural y espiritual que resulta de permitir que la ciencia y la fe se critiquen y edifiquen positivamente la una a la otra.

\section{Conclusiones}

La visión de conflicto entre la ciencia y la religión es obsoleta, falsa y está mayormente desacreditada. Los estudios han demostrado que esta visión es una cosmovisión inventada para justificar las agendas político-académicas de ciertos grupos sociales en Gran Bretaña y en Estados Unidos durante la segunda mitad del siglo XIX y comienzos del siglo XX porque enfrentaba a los científicos clérigos aferrados a la Escritura con los nuevos científicos de la academia orientados con mente independiente, estos últimos defensores de la idea de que la religión era una barrera el progreso de la ciencia. Solo la insistencia en algunos círculos acadé- 
micos obsesivos ha mantenido esta visión todavía en consideración, pues la evidencia histórica no la sostiene. Numerosos estudios han mostrado que a lo largo de la historia la ciencia se ha desarrollado no a pesar de sino gracias a la religión cristiana, que proporcionó un marco de pensamiento epistemológico adecuado para el ejercicio racional de la investigación y el conocimiento de la naturaleza y del hombre. La mayoría de los pensadores que no ven la ciencia y la religión como enemigas, pero tampoco como cercanas, tienden a considerarlas como entidades independientes y separadas, pero no necesariamente en conflicto.

A pesar de la creciente opinión de que la ciencia y la religión no están en guerra entre ellas, todavía quedan filósofos, científicos y una parte de la población general que entiende la relación entre la ciencia y la religión como un choque, un antagonismo o rivalidad que no tiene solución. Pero estamos convencidos de que esa postura es una idea heredada de una falsa concepción de la historia de la ciencia y la religión. Aunque no se puede decir que el cristianismo dio origen a la ciencia moderna, está claro que hay una sinergia fundamental entre ambas que hace que funcionen en asociación. Como hemos señalado, la fe cristiana proporciona un marco intelectual conducente al razonamiento y descubrimiento científico. Los historiadores de la ciencia ahora sostienen que hubo factores religiosos significativos en el surgimiento y éxito de la ciencia moderna en Occidente. De nuevo, no sólo muchas figuras clave en las ciencias naturales fueron y son creyentes con compromisos religiosos sinceros, sino que sus descubrimientos fueron posibles gracias a que partían de presuposiciones religiosas, particularmente la noción cristiana de creación ordenada, predecible y estable.

Nosotros sostenemos que, aunque no hay un conflicto inherente entre la fe y la ciencia, queda en muchos pensadores científicos e incluso teólogos la actitud de conflicto que deriva de una aproximación equivocada a ambos campos del conocimiento. Esa actitud de conflicto se expresa en cuatro áreas de la interacción: 1) conflicto en cuanto al qué epistemológico, es decir, qué cuenta a la hora de llegar a la verdad, qué cuenta como conocimiento verdadero; 2) conflicto en cuanto a quién tiene autoridad para llegar a la verdad o determinar qué es verdad; 3 ) conflicto en cuanto al origen y sentido de la moralidad; y 4) conflicto en cuanto al sentido y propósito de la vida, con especial énfasis en el ser humano.

Nuestra experiencia educativa y nuestra interacción con investigadores nos lleva a concluir que tales conflictos no son derivados de ningún tipo de evidencia, sea científica o religiosa, sino de una postura a priori proclive a ver la relación entre la ciencia y la fe como conflictiva que condiciona el diálogo, la cooperación, y el entendimiento.

\section{Referencias Bibliográficas}

Alexander, D. (2007). Models for relating science and religion. The Faraday papers, (3), 4. Recuperado de https://bit.ly/2QHeEMR

Alexander, R. (1987). The biology of moral systems. Nueva York, NY: Aldine De Gruyter.

Allen, C. y Neal, J. (2019). Teleological notions in biology. En E. Zalta (Ed.), The Stanford encyclopedia of philosophy. Recuperado de https://stanford.io/36s36Uk 
Alvira Domínguez, R. (2002). Fe en la razón y razón en la fe. Humanidades, 2(1), 15-21. Recuperado de https://bit.ly/2Fe2R3i

Ayala, F. (1987). The biological roots of morality. Biology and philosophy, 2(3), 235-252, https://doi.org/10.1007/bf00128831.

Barash, D. (27 de Octubre de 2014). God, Darwin and my college biology class. The New York Times. Recuperado de https://nyti.ms/2FafSel

Barbour, I. (2004). El encuentro entre ciencia y religión. ¿Rivales desconocidas o compañeras de viaje? Santander: Sal Terrae.

Begley, S. y Westley, M. (20 de Julio de1998). Science finds God. Newsweek, 132(3), 46-51. Recuperado de https://wapo.st/2MOQ8Zn

Bowler, P. (2009). Evolution: the history of an idea. Berkeley, CA: University of California Press.

Bowler, P. (2012). Christian responses to darwinism in the later nineteenth century. En J. Stump y A. Padgett (Eds.), The blackwell companion to science and christianity (pp. 37-47). Cambridge: Blackwell.

Brand, L. (2003). The integration of faith and science. Journal of the adventist theological society, 14(1), 121-137. Recuperado de https://bit.ly/37qFMGQ

Brooke, J. (1991). Science and religion: some historical perspectives. Cambridge: Cambridge University Press.

Brooke, J. (2001). The Wilberforce-Huxley debate: why did It happen? Science \& christian belief, 13(2), 127-141. Recuperado de https://bit.ly/2uapmEd

Buckley, M. (1987). At the origins of modern atheism. New Haven, CT: Yale University Press.

Carroll, S. (23 de Junio de 2009). Science and religion are not compatible. Recuperado de https://bit.ly/36hd62W

Comité ad hoc para la supervisión del uso del catecismo de la Iglesia Católica de la conferencia de obispos católicos de los Estados Unidos (2007). Catecismo católico de los Estados Unidos para los adultos. (2007). Washington, DC: Conferencia de obispos católicos de los Estados Unidos. Recuerado de https://bit.ly/2ZNx8j1

"Standing up in the milky way". Cosmos: a spacetime odyssey, season 01, episode 01, National Geographic Channel, 9 Mar. 2014.

Chambers, R. (1844). Vestiges of the natural history of creation. Londres: John Churchill.

Collins, F. (2016). ¿Cómo habla Dios? La evidencia científica de la fe. Madrid: Ariel.

Darwin, C. (1971). El origen del hombre. Valencia: F. Sempere y Co.

Davis, P. (2006). The Goldilocks enigma: why is the universe just right for life?. London: Allen Lane.

Dawkins, R. (1982). Replicators and vehicles. En King's College Sociobiology Group (Eds.), Current problems in sociobiology (pp. 161-180). Cambridge: Cambridge University Press.

Dawkins, R. (1995). River out of Eden: a Darwinian view of life. New York, NY: Basic Books. 
de Waal, F. , Smith Churchland, P. , Pievani, T. y Parmigiani, S. (Eds.). (2014). Evolved morality: the biology and philosophy of human conscience. Boston, MA: Brill. https://doi.org/10.1163/9789004263888.

Depew, D. y Weber, B. (2011). The fate of darwinism: evolution after the modern synthesis. Biological theory, 6(1), 89-102. https://doi.org/10.1007/s13752-011-0007-1.

Desmond, A. y Moore, J. (1991). Darwin. London: Michael Joseph.

Easterbrook, G. (1997). Science and God: a warming trend?. Science, 277(5328), 890-893. https://doi:10.1126/science.277.5328.890.

Ecklund, E. y Scheitle, C. (2007). Religion among academic scientists: distinctions, disciplines, $\begin{array}{lll}\text { and } \text { demographics. Social 289-307. } & \text { 54(2), }\end{array}$ https://doi.org/10.1525/sp.2007.54.2.289.

Evans, C. (2015). Why Christian faith still makes sense. A responde to contemporary challenges. Grand Rapids, Ml: Baker Academic.

Farber, P. (1994). The temptations of evolutionary ethics. Berkeley, CA: University of California Press.

Gillespie, N. (1979). Charles Darwin and the problem of creation. Chicago, IL: University of Chicago Press.

Goodenough, U. y Deacon, T. (2003). From biology to consciousness to morality. Zygon, 38(4), 801-819. https://doi.org/10.1111/j.1467-9744.2003.00540.x.

Gould, S. (1977). Ever since Darwin. London: Penguin.

Gould, S. (1983). Extemporaneous comments on evolutionary hope and realities. En C. Hamrum (Ed.), Darwin's legacy: Nobel conference XVIII (pp. 95-103). San Francisco, CA: Harper and Row.

Hannam, J. (2011). The genesis of science. How the christian middle ages launched the scientific revolution. Washington, DC: Regnery Publishing.

Hannam, J. (05 de Mayo de 2011). Science owes much to both christianity and the middle ages. Recuperado de https://go.nature.com/2sC6Hk4

Harrison, P. y Lindberg, D. (2011). Early christianity. En J. Brooke y R. Numbers (Eds.), Science and religion around the world (pp. 67-91). Oxford: Oxford University Press.

Haught, J. (2008). God and the new atheism: a critical response to Dawkins, Harris, and Hitchens. Louisville, KY: Westminster John Knox Press.

Hawking, S. (1988). Breve historia del tiempo: del big bang a los agujeros negros. (M. Ordoño, Trad.). México, DF: Grijalbo.

Hawking, S. y Mlodinow, L. (2010). El gran diseño. (D. Jou i Mirabent, Trad.). Barcelona: Crítica. Hutchinson, I. (2007). Warfare and wedlock: redeeming the faith-science relationship. Perspectives on science and christian faith, 59(2), 91-101. Recuperado de https://bit.ly/2Fe2lgi

Huxley, J. (1942). The modern synthesis. London: Allen and Unwin. 
James, F. (2005). An 'Open clash between science and the church'?: Wilberforce, Huxley and Hooker on Darwin at the british association, Oxford, 1860. En D. Knight y M. Eddy (Eds.), Science and beliefs: from natural philosophy to natural science 1700-1900 (pp. 171-193). Aldershot: Ashgate. https://doi.org/10.4324/9781315243733-15.

Joyce, R. (2006). The evolution of morality. Cambridge, MA: The MIT Press.

Katz, B. (2004). The fifth narrative: the wiser ascend of Icarus. Bloomington, IN: Authorhouse.

Katz, L. (Ed.) (2000). Evolutionary origins of morality: cross-disciplinary studies. Exeter: Imprint Academic.

Koonin, E. (2009). The Origin at 150: is a new evolutionary synthesis in sight?. Trends in genetics, 25(11), 473-475. https://doi.org/10.1016/j.tig.2009.09.007.

Krebs, D. (2011). The origins of morality: an evolutionary account. Oxford: Oxford University Press.

Larsen, T. (2008). "War is over, if you want it": beyond the conflict between faith and science. Perspectives on science and christian faith, 60(3), 147-155. Recuperado de https://bit.ly/2ucYfbL

Leuba, J. (1934). Religious beliefs of American scientists. Harper's magazine, 169(8), 291-300. Recuperado de https://bit.ly/36hOUxp

Lewontin, R. (1997). Billions and billions of demons [Reseña del libro The demon-haunted world: science as a candle in the dark de Carl Sagan]. The New York review of books, 44 (1). Recuperado de https://bit.ly/2QIx5AQ

Lindberg, D. y Numbers, R. (1987). Beyond war and peace: a reappraisal of the encounter between christianity and science. Perspectives on science and christian faith, 39(3), 140-149. Recuperado de https://bit.ly/2SJF6Z2

Mayr, E. (1972). The nature of the darwinian revolution. Science, 176(4038), 981-989. https://doi.org/10.1126/science.176.4038.981.

McGrath, A. (2015). The big question. Why we can't stop talking about science, faith and God. Nueva York, NY: St. Martin's Press.

McGrath, A. (2017). The great mystery. Science, God and the human quest for meaning. London: Hodder \& Stoughton.

Monod, J. (1971). Chance and necessity. Glasgow: William Collins and Sons.

Monterosso, J., Royzman, E. y Schwartz, B. (2005). Explaining away responsibility: effects of scientific explanation on perceived culpability. Ethics and behavior, 15(2), 139-158. https://doi.org/10.1207/s15327019eb1502_4

Moore, J. (1981). The post-darwinian controversies: a study of the protestant struggle to come to terms with Darwin in Great Britain and America, 1870-1900. Cambridge: Cambridge University Press.

Moss, L. (1992). A Kernel of truth? On the reality of the genetic program. PSA: Proceedings of the biennial meeting of the Philosophy of Science Association 1992, (1), 335-348. https://doi.org/10.1086/psaprocbienmeetp.1992.1.192766. 
Nagel, T. (1997). The last word. Oxford: Oxford University Press.

Nagel, T. (2012). Mind and cosmos: why the materialist neo-darwinian conception of nature is almost certainly false. Oxford: Oxford University Press.

Nash, R. (1992). Worldviews in conflict. Choosing christianity in the world of ideas. Grand Rapids, Ml: Zondervan.

Ortega y Gasset, J. (1967). El origen deportivo del estado. Citius, altius, fortis, 9(1), 259-276. Recuperado de https://bit.ly/2Qg2wDK

Papp, D. (1993). Darwin. La aventura de un espíritu. Madrid: Espasa-Calpe.

Provine, W. (1988a). Evolution and the foundation of ethics. MBL Science, 3(1), 25-29.

Provine, W. (1988b). Scientists face it! Science and religion are incompatible. The Scientist, (16). Recuperado de https://bit.ly/2QzHGhy

Rasi, H. (2003). El cristiano ante la fe y la razón. Diálogo, 15(3), 5-9. Recuperado de https://bit.ly/2STNI4C

Rees, M. (2000). Just six numbers: The deep forces that shape our universe. London: Phoenix.

Rushdie, S. (1990). Is nothing sacred? The Herbert Read memorial lecture. Cambridge: Granta.

Schmidt, A. (2004). How Christianity changed the world. Grand Rapids, Ml: Zondervan.

Sequeiros, L., Martínez de la Fe, J. y Prieto Santana, M. (2010). Stephen Hawking, The grand design y los medios de comunicación: filosofía, ciencia y religión. Pensamiento, 66(249), 809832. Recuperado de https://bit.ly/2QfPvKq

Simpson, G. (1967). The meaning of evolution. New Haven, CT: Yale University Press.

Spradley, J. (2005). How have Christian faith and natural science interacted in history? En D. Chappell y E. Cook (Eds.), Not just science. Questions where Christian faith and natural science intersect (pp. 27-57). Grand Rapids, Michigan: Zondervan.

Stark, R. (2004). For the glory of God. How monotheism led to reformations, science, witchhunts, and the end of slavery. Princeton: Princeton University Press.

Stenmark, M. (2004). How to relate science and religion. Grand Rapids, MI: Eerdmans.

Talbott, S. (2017). Evolution and the purposes of life. The New Atlantis, (51), 63-91. Recuperado de https://bit.ly/2u7bQkA

Theißen, G. (2009). Saltational evolution: hopeful monsters are here to stay. Theory in biosciences, 128(1), 43-51. https://doi.org/10.1007/s12064-009-0058-z.

Turner, F. (1978). The victorian conflict between science and religion: a professional dimension. Isis, 69(248), 356-376. https://doi.org/10.1086/352065.

Whitfield, J. (2008). Biological theory: postmodern evolution?. Nature, 455(7211), 281-284. https://doi.org/10.1038/455281a.

Wilson, C. (2010). Darwinian morality. Evolution: education and outreach, 3(2), 275-287. https://doi.org/10.1007/s12052-009-0162-z. 
Wolf, S. (2010). Meaning in life. Princeton, NJ: Princeton University Press.

Wong, P. (Ed.) (2013). The human quest for meaning: theories, research, and applications. New York, NY: Routledge.

Zinke, E. (2004). Faith-Science issues: an epistemological perspective. Journal of the adventist theological society, 15(1), 63-90. Recuperado de https://bit.ly/2MNZLHw

\section{Para citar este artículo bajo Norma APA 6a ed. \\ Ayala Choque, J. y Esperante, R. (2019). ¿Están la ciencia y la \\ fe en conflicto? Depende de lo que se entienda por 'conflic- \\ to'. Cuadernos de Teología - Universidad Católica del Norte \\ (En línea), 11, e3830, https://doi.org/10.22199/issn.0719- \\ 8175-2019-0007}

Copyright del articulo: @2019 Judith Ayala y Raúl Esperante

Este es un artículo de acceso abierto, bajo licencia Creative Commons BY 4.0

\section{DOI}

